Article

\title{
Sensitivity Analysis and Optimization of Operating Parameters of an Oxyfuel Combustion Power Generation System Based on Single-Factor and Orthogonal Design Methods
}

\author{
Zhiyu Zhang ${ }^{1,2,3, *}$, Rongrong Zhai ${ }^{1}$, Xinwei Wang ${ }^{1}$ and Yongping Yang ${ }^{1, *}$ \\ 1 Key Laboratory of Power Station Energy Transfer Conversion and System of Ministry of Education, \\ North China Electric Power University, Beijing 102206, China; zhairongrong01@163.com (R.Z.); \\ wxw15524369777@163.com (X.W.) \\ 2 School Energy and Environment, Inner Mongolia University Science \& Technology, Baotou 014010, China \\ 3 Inner Mongolia Key Laboratory of Efficient and Clean Combustion, Inner Mongolia University Science \& \\ Technology, Baotou 014010, China \\ * Correspondence: zzy0021@126.com (Z.Z.); yyp@ncepu.edu.cn (Y.Y.); \\ Tel.: +86-472-5951-568 (Z.Z.); +86-10-6177-2000 (Y.Y.)
}

Received: 18 January 2020; Accepted: 20 February 2020; Published: 23 February 2020

\begin{abstract}
The main purpose of this paper is to quantitatively analyze the sensitivity of operating parameters of the system to the thermodynamic performance of an oxyfuel combustion (OC) power generation system. Therefore, the thermodynamic model of a $600 \mathrm{MW}$ subcritical OC power generation system with semi-dry flue gas recirculation was established. Two energy consumption indexes of the system were selected, process simulation was adopted, and orthogonal design, range analysis, and variance analysis were used for the first time on the basis of single-factor analysis to conduct a comprehensive sensitivity analysis and optimization research on the changes of four operating parameters. The results show that with increasing oxygen purity, the net standard coal consumption rate first decreases and then increases. With decreasing oxygen concentration, the recirculation rate of dry flue gas in boiler flue gas $\left(\chi_{1}\right)$ and an increasing excess oxygen coefficient, the net standard coal consumption rate increases. The net electrical efficiency was just the opposite. The sensitivity order of two factors for four indexes is obtained: the excess oxygen coefficient was the main factor that affects the net standard coal consumption rate and the net electrical efficiency. The influence of oxygen concentration and oxygen purity was lower than that of excess oxygen coefficient, and $\chi_{1}$ has almost no effect.
\end{abstract}

Keywords: energy consumption; operating factors; orthogonal design; oxyfuel combustion; sensitivity analysis

\section{Introduction}

Increasing greenhouse gas emissions are one of the main reasons for the frequent occurrence of global extreme weather. $\mathrm{CO}_{2}$ comprises approximately $80 \%$ of those emissions [1]; therefore; reducing $\mathrm{CO}_{2}$ emissions to cope with global climate change is one of the greatest challenges facing mankind in energy production today. A promising technology for power generation that reduces $\mathrm{CO}_{2}$ emissions is oxyfuel combustion (OC) with carbon capture. In this type of power plant; the fuel is burned in an $\mathrm{O}_{2} / \mathrm{CO}_{2}$ atmosphere; producing flue gas consisting mainly of $\mathrm{CO}_{2}$ and $\mathrm{H}_{2} \mathrm{O}$ [2].

As a near-zero-emission clean coal power generation technology that can directly capture $\mathrm{CO}_{2}$, OC technology is a commercially feasible technology for large-scale $\mathrm{CO}_{2}$ capture [3]. However, 
large-scale carbon capture coal-fired generating units using OC technology need to use an air separation unit and $\mathrm{CO}_{2}$ purification and compression unit. The high energy consumption incurred by these additional types of equipment leads to a decrease in the overall generating efficiency of the units and an increase in operating costs, which are the main obstacles to their large-scale use [4]. Therefore, it is necessary to conduct a comprehensive and in-depth analysis of the relevant operational factors that affect those obstacles. These analyses are important for reducing unit energy consumption, promoting large-scale use of $\mathrm{OC}$ technology, and reducing $\mathrm{CO}_{2}$ capture cost.

Extensive work has been done on operation energy consumption and techno-economic analysis of $\mathrm{OC}$ and $\mathrm{CO}_{2}$ capture units. Han [5] and Jin [6] used an exergy analysis method to analyze the thermodynamic performance of an air-separation oxygen system and a $\mathrm{CO}_{2}$ capture system. They also proposed ways to reduce the operating energy consumption of the systems. Tola [7] and Oboirien [8] did a techno-economic analysis on the operating energy consumption, equipment investment, power generation cost, and $\mathrm{CO}_{2}$ emission reduction cost of coal-fired generating sets that used $\mathrm{OC}$ and a $\mathrm{CO}_{2}$ capture system. They concluded that the $\mathrm{CO}_{2}$ emission rate was reduced by 10 times after the power plant was modified with oxyfuel technology, and $27 \%$ to $29 \%$ of the energy was used to capture $\mathrm{CO}_{2}$. The energy loss was related to the nature of coal. $\mathrm{Fu}[9]$ proposed applying process heat to the Rankine cycle of regenerative steam to increase the power generation of the steam turbine in an OC power plant. Yan [10] did a comprehensive sensitivity analysis on a 600MW supercritical steam oxyfuel combustion power generation system using dry, semidry, and wet flue gas recycling modes. After evaluating the changes in eight main operating parameters, he concluded that air leakage had the greatest influence on the output energy of the system and that the most practical flue gas recirculation mode was the semidry type. Gładysz [11] and Koiwanit [12] adopted the method of total life cycle cost of coal-fired units before and after the modification of OC equipment investment, power generation cost, and $\mathrm{CO}_{2}$ emission reduction cost, and put forward a different method of life cycle assessment. Jin [13], Kong [14], and Han [15], through modeling and process simulation, analyzed and evaluated $\mathrm{OC}$ and $\mathrm{CO}_{2}$ capture generator sets from the perspective of thermal dynamics and thermal economics. They then proposed the best value of oxygen concentration and an optimization scheme for reducing system energy consumption. Escudero [16] proposed technology for an oxyfuel coal-fired power plant that uses a high-concentration oxidizer of over $40 \%$ and integrates waste heat into the new steam cycle to minimize energy consumption. The net efficiency of their power plant was significantly higher than that of a benchmark oxyfuel plant, and the energy penalty could be reduced from $10.5 \%$ to $7.3 \%$. Gładysz [17] and Ziębik [18] used cumulative exergy loss, local exergy loss, and a thermodynamic system to devise a perfect degree of cumulative exergy efficiency. They analyzed three techno-economic indexes such as the $\mathrm{OC}$, the $\mathrm{CO}_{2}$ capture generating set, and the thermodynamic performance of the system. Lei [19] proposed a new OC process. Its capital investment and the operation costs of the air separation unit and the circulating fan were lower. The variation of flue gas composition in the flue gas combustion furnace was small, and when the ratio of air to oxygen was 2 or 3, the economy of the OC was better. Gao [20] used a Peng-Robinson (PR) equation of state model on the basis of the actual gas state equation to establish a method using a bias function and $\mathrm{a}_{2}$ compressed air separation unit to calculate the operation energy consumption of a purification unit.

Previous studies have mostly analyzed the influence of one or several single operating factors on the energy efficiency indicators of an OC power generation system. For example, Jin [13] analyzed the influence of oxygen concentration on the net efficiency. Kong [14] and Han [15] analyzed the influence of oxygen purity on net efficiency. Yan [10] undertook a comparative analysis and evaluation on the influence of such parameters as flue gas recirculation rate, air leakage rate, pressure rise of fans, flue gas condensation temperature, oxygen concentration, and flue gas circulation model on the net efficiency. However, in a uniform experiment or simulation platform, the main operation parameters, such as the oxygen purity in the air separation unit, the oxygen concentration and excess oxygen coefficient in power generation unit, and the recirculation rate of dry flue gas in boiler flue gas for quantitative analysis of the operating energy indexes of in-depth research has yet to carry out in-depth 
research. These operating economic indexes include the net standard coal consumption rate and the net electrical efficiency, among which the net standard coal consumption rate can comprehensively reflect the overall operating energy consumption level of a power generation system.

Moreover, due to a large number of influencing parameters in the study of thermodynamic characteristics of an OC power generation system, each parameter has a certain range of variation. How to consider the interaction between parameters requires a comprehensive analysis of each parameter's collocation, so the calculation will be very large. Therefore, the single factor analysis method with fixed other parameters was mostly used in previous studies. However, this method cannot determine the optimization order of each factor and the influence of the interaction between each factor on the system performance.

An orthogonal design method is a design method to study multi-factors and multi-levels. This method selects representative points from the overall test according to the orthogonality for the test, which can solve the coupling effect of multi-factors and reduce the number of tests [21,22].

At present, the orthogonal design method is often used in the design and parameter optimization of different power generation systems and cycles. For example, Wang [23] and Liu [24] established the thermodynamic model of the organic Rankine circulation system, and through the analysis of the orthogonal design results, the optimal level composition of system parameters to improve the thermal and economic performance of the system was given. $\mathrm{Xi}$ [25] analyzed the experimental system of a new organic Rankine cycle based on the range analysis method of orthogonal design and obtained the optimal and the worst constitutions of six indexes. Chiu [26] conducted an experimental study on the reaction conditions of methanol steam reforming, obtained the influence of each reaction condition on the MSR process, and obtained the optimal combination of each control factor. Chen [27] and Terzioğlu [28], respectively, analyzed the performance of the thermoelectric generator by the orthogonal design method and obtained the influence relationship of material and geometric parameters on system performance. However, the application of an orthogonal design method to the optimization of operating parameters in an OC power generation system has not been carried out yet.

The purpose of this study is to take the net standard coal consumption and the net electrical efficiency of the system as specific energy efficiency indicators, study the sensitivity characteristics of various single factors under a unified platform, and obtain the results of comprehensive sensitivity analysis of operating parameters to improve the thermal performance and economic performance of the OC power generation system through orthogonal design method, range analysis, and variance analysis for the first time. This study will provide theoretical guidance for the engineering design and optimization of an OC power generation system.

\section{Method}

\subsection{Model of the Oxyfuel Combustion System}

We used Aspen Plus (Aspen Technology, Inc., USA) [29] and EBSILON Professional (STEAG Gmbh, Germany) [30] software to model an OC power generation system based on the conventional subcritical coal-fired units currently in operation. Four operating parameters, including oxygen purity, oxygen concentration, the recirculation rate of dry flue gas in boiler flue gas $\left(\chi_{1}\right)$, and the excess oxygen coefficient, were selected as factors. The power station modeled in this study included three units: OC power generation unit, air separation unit (ASU), and flue gas compression and purification unit (CPU). Figures 1-3 showed the details of each unit.

\subsubsection{OC Power Generation Unit}

Currently, 600 MW OC power generation units have not been put into operation. Thus, we selected a $600 \mathrm{MW}$ subcritical generating unit as the reference unit in this study. The unit had a rated power of $600 \mathrm{MW}$ and a maximum continuous output of 641.6 MW. The boiler model was SG-2023/17.5-M914, and the design fuel was shenhua wanlichuan bituminous coal. An analysis of the coal is shown in 
Table 1. The turbine model was N600-16.67/538/538. The regenerative system consisted of a three-stage high-pressure heater, a four-stage low-pressure heater, and a deaerator. The specific process is shown in Figure 1.

Table 1. Coal analysis.

\begin{tabular}{cccccccc}
\hline $\mathbf{C}_{\mathrm{ar}}$ & $\mathbf{H}_{\mathrm{ar}}$ & $\mathbf{N}_{\mathrm{ar}}$ & $\mathbf{O}_{\mathrm{ar}}$ & $\mathbf{S}_{\mathrm{ar}}$ & $\mathbf{A}_{\mathrm{ar}}$ & $\mathbf{M}_{\mathrm{ar}}$ & $\mathbf{L H V ~ ( k J / k g )}$ \\
\hline 52.20 & 2.47 & 0.98 & 8.42 & 0.73 & 10.39 & 24.81 & 18,852 \\
\hline
\end{tabular}

The subscript "ar" indicates the as-received basis. LHV indicates a low heating value.

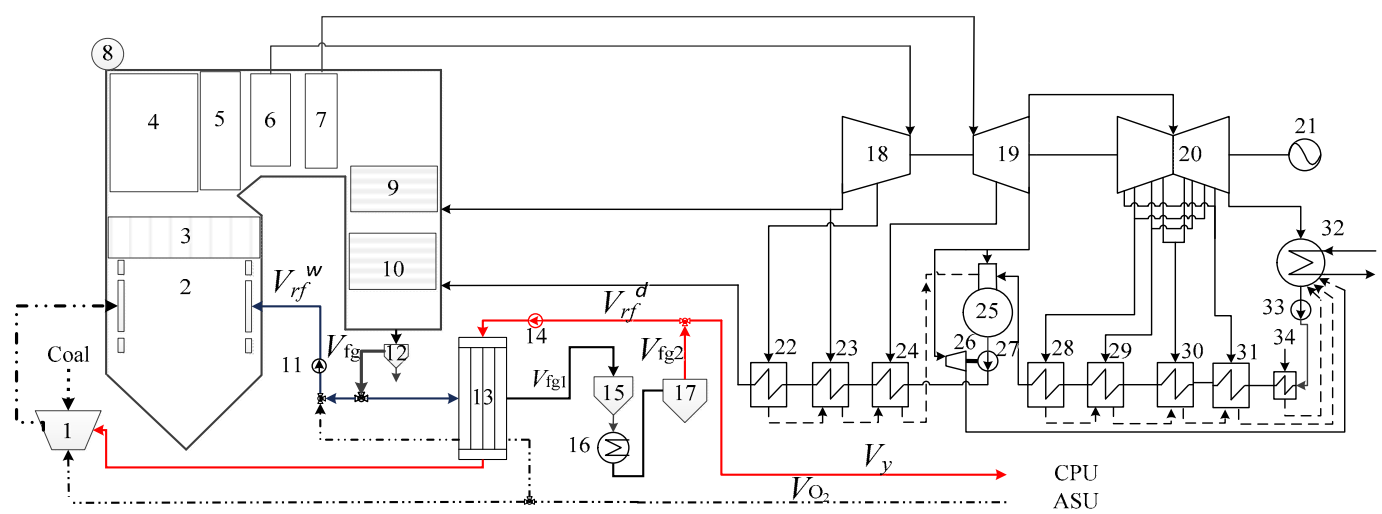

Figure 1. OC power generation unit. Subunits are as follows: 1 . Coal grinder; 2. Chamber of a stove or furnace; 3 . Wall reheater; 4 . Screen superheater; 5 . Rear panel superheater; 6 . High-temperature superheater; 7. High-temperature reheater; 8. Drum; 9. Low-temperature reheater; 10. Economizer; 11. Secondary flue gas (wet flue gas) recirculating fan; 12. Dust remover; 13. Gas-gas heat exchanger; 14. Primary flue gas (dry flue gas) recirculating fan; 15. Flue-gas desulfurizer; 16. Low-temperature economizer; 17. Direct contact dehydration unit; 18. High-pressure cylinder; 19. Medium-pressure cylinder; 20. Low-pressure cylinder; 21. Generator; 22-24. High-pressure heater; 25. Deaerator; 26. Feed pump; 27. Generator; 28-31. Low-pressure heater; 32. Condenser; 33. Condensate pump; 34. Shaft sealing heater.

The flow of the modeled OC power generation system was basically the same as that of a reference conventional combustion generation system. The difference was that the combustion gas in the OC power generation system was a proportional mixture of circulating flue gas and oxygen, not air. The OC power generation system could be divided into two types, dry cycle and wet cycle, according to the temperature and water content of the circulating flue gas. The dry cycle dusted and cooled the flue gas to remove part of its moisture in the furnace and oxygen to participate in the combustion. The wet cycle pumped part of the hot flue gas directly into the furnace from behind the economizer. In this model, semi-dry flue gas recirculation was used. That is, the dry cycle was used for the primary gas flow, and the wet cycle was used for the secondary gas flow [10,11].

For the OC boiler with primary air as dry flue gas and secondary air as wet flue gas recirculation, after entering the stable operation stage, $V_{\mathrm{O}_{2}}, V_{r f}^{d}$, and $V_{r f}^{w}$ in the flue gas circulation process should satisfy:

$$
\begin{gathered}
\frac{V_{\mathrm{O}_{2}} \varphi_{\mathrm{O}_{2}}+V_{r f}^{d} O_{r f}^{d}+V_{r f}^{w} O_{r f}^{w}}{V_{O_{2}}+V_{r f}^{d}+V_{r f}^{w}}=r_{O_{2}} \\
V_{O_{2}}+V_{r f}^{d}+V_{r f}^{w}=V_{f} \\
V_{r f}^{d}+V_{r f}^{w}=V_{r f}
\end{gathered}
$$


where $V_{\mathrm{O}_{2}}$ is the oxygen flow rate output by ASU, $\mathrm{Nm}^{3} / \mathrm{h} ; \varphi_{\mathrm{O}_{2}}$ is the oxygen purity, $\%$. The oxygen purity is defined as the molar proportion of pure oxygen contained in the oxygen fed into the OC generating unit from the air separation unit; $V_{r f}^{d}$ is the circulating dry flue gas flow rate, $\mathrm{Nm}^{3} / \mathrm{h} ; O_{r f}^{d}$ is the oxygen volume content in the recirculating dry flue gas after dehydration and drying by the dehydration device, \%; $V_{r f}^{w}$ is the recirculating wet flue gas flow rate, $\mathrm{Nm}^{3} / \mathrm{h} ; \mathrm{O}_{r f}^{w}$ is the oxygen volume content in the recirculating wet flue gas without dehydration and drying by the dehydration device, $\%$; $r_{\mathrm{O}_{2}}$ is the oxygen concentration in all combustion-supporting gases, $\%$. The oxygen concentration is defined as the molar proportion of oxygen in the auxiliary gas fed into the OC power generation unit; $V_{f}$ is the actual volume of combustion supporting gas required for the combustion process of the OC pot, $\mathrm{Nm}^{3} / \mathrm{h} ; V_{r f}$ is the total circulating flue gas flow rate, $\mathrm{Nm}^{3} / \mathrm{h}$.

Two important definitions of a flue gas cycle rate are

$$
\begin{gathered}
\chi=\frac{V_{r f}^{d}}{V_{f g}} \\
\chi_{1}=\frac{V_{r f}^{d}}{V_{f g 2}}
\end{gathered}
$$

where $\chi$ is the recirculation rate of dry flue gas in the total flue gas, $\chi_{1}$ is the recirculation rate of dry flue gas in the boiler flue gas. The dry flue gas mentioned here refers to the flue gas after desulfurization and direct contact dehydration unit. $V_{f g}$ is the total flue gas of the boiler, $\mathrm{Nm}^{3} / \mathrm{h} ; V_{f g 1}$ is the boiler flue gas flow rate, $\mathrm{Nm}^{3} / \mathrm{h} ; V_{f g}$ is the total flue gas volume after gas heat transfer, desulfurization, and direct contact dehydration, $\mathrm{Nm}^{3} / \mathrm{h}, V_{y}$ is the volume flow of flue gas into the CPU.

We used EBSILON Professional software to establish models for a conventional power plant and the OC power generation system. In the single-factor analysis of OC conditions, the simulation parameters were set as follows:

- The coal used was the same as that of conventional coal-fired units.

- The combustion process of the boiler was under $0.097 \mathrm{MPa}$ of pressure.

- The oxygen temperature after preheating was $351{ }^{\circ} \mathrm{C}$ : the same as the air temperature of the conventional combustion power generation system after preheating.

- The inlet oxygen temperature of the gas-gas heat exchanger was set at $45^{\circ} \mathrm{C}$.

- The pulverized coal burnout rate was $98 \%$.

- To ensure the coal burnout rate, the excess oxygen coefficient was 1.10.

- The air leakage coefficient of the system was 3\%.

- The oxygen purity $\left(\varphi_{\mathrm{O}_{2}}\right)$ was set at $96 \%$; the nitrogen content was $0.8 \%$, the argon content was $3.2 \%$.

- The oxygen concentration $\left(r_{\mathrm{O}_{2}}\right)$ was set to $33 \%$.

- $\chi_{1}$ was $55 \%$.

The proportion of primary and secondary gas mixture, the oxygen concentration, and the oxygen supply (the difference between the total oxygen demand and the oxygen in the circulating flue gas) were all set and calculated by the controller in EBSILON. The simulation results and design values of the conventional unit and the oxyfuel unit are shown in Table 2. Table 2 shows that the difference between the design value of the conventional unit and the simulation value of the conventional unit was very small, thus verifying the accuracy of the model.

Cryogenic oxygen production is the only commercial large-scale oxygen production method, which can be divided into external compression and internal compression. According to the applied pressure level, oxygen production level, and technical perfection, this study selected five sets of air separation units with a single machine capable of $6 \times 10^{4} \mathrm{Nm}^{3} / \mathrm{h}$ for external compression flow. After simplifying the process, Aspen Plus software was applied to establish the air separation unit model of the OC generator set based on the PR state equation of real gas. 
In the process of oxygen production, the air separation unit separates the compressed air into oxygen with purity $\varphi_{\mathrm{O}_{2}}$ and nitrogen with purity $\varphi_{\mathrm{N}_{2}}$ through the rectification device. The actual separation work required in the separation process is as follows:

$$
\begin{array}{r}
W_{s}=\frac{R T_{0}}{\eta_{e}}\left\{n_{\mathrm{O}_{2}}\left[\frac{\varphi_{\mathrm{O}_{2}}}{100} \ln \frac{\varphi_{\mathrm{O}_{2}}}{100-\varphi_{\mathrm{O}_{2}}}+\ln \left(1-\frac{\varphi_{\mathrm{O}_{2}}}{100}\right)\right]+\right. \\
n_{\mathrm{N}_{2}}\left[\frac{\varphi_{\mathrm{N}_{2}}}{100} \ln \frac{\varphi_{N_{2}}}{100-\varphi_{\mathrm{N}_{2}}}+\ln \left(1-\frac{\varphi_{\mathrm{N}_{2}}}{100}\right)\right]- \\
\left.\quad\left(\frac{\varphi_{m, \mathrm{O}_{2}}}{100} \ln \frac{\varphi_{m, O_{2}}}{100}+\frac{\varphi_{m, N_{2}}}{100} \ln \frac{\varphi_{m, N_{2}}}{100}\right)\right\}
\end{array}
$$

where $W_{s}$ is actual separation work required in the separation process, $\mathrm{J}$; the $T_{0}$ is the environment temperature, $\mathrm{K} ; R$ is the gas constant, $\mathrm{J} /(\mathrm{mol} \cdot \mathrm{K}) ; \varphi_{m, O_{2}}$ and $\varphi_{m, N_{2}}$ are, respectively, the volume fractions of oxygen and nitrogen in the air, \%; $n_{\mathrm{O}_{2}}$ is the amount of oxygen with the purity $\varphi_{\mathrm{O}_{2}}$ obtained after the separation of one mole of air, mol; $n_{N_{2}}$ is the amount of nitrogen with the purity of $\varphi_{\mathrm{N}_{2}}$ obta ined after the separation of one mole of air.

Before entering the rectification system for separation, the air needs to be compressed by the multistage compressor to improve the exergy value, so as to achieve the actual separation work $W_{s}$ required by the separation process. Therefore, at the outlet of the multistage compressor, the flow pressure $p$ required by the air is:

$$
p=p_{0} \exp \left(\frac{W_{s}}{T_{0} R}\right)
$$

where $p_{0}$ is inlet air pressure of the multistage compressor, MPa.

\subsubsection{Air Separation Unit}

The operating energy consumption of the air separation unit can be calculated by the electrical power $E_{A S U}$ required to produce oxygen with the purity of $\varphi_{\mathrm{O}_{2}}$ and a flow rate of $V_{\mathrm{O}_{2}}$.

$$
E_{A S U}=\frac{\Sigma\left(\varphi_{g, l} \sum_{i}^{n} W_{i,(g, l)}^{0}\right)\left(\varphi_{\mathrm{O}_{2}}+\varphi_{N_{2}}-100\right) V_{O_{2}}}{22.4 \eta_{\operatorname{com}}\left(\varphi_{g, O_{2}}+\varphi_{N_{2}}-100\right)}
$$

where $\varphi_{g, l}$ is the volume fraction of $l$ gas contained in the air, $\% ; n$ is the multistage compressor series; $W_{i,(g, l)}^{0}$ is the theoretical compression work required for the adiabatic compression of $l$ gas in the air by the first stage of the multistage compressor, $\mathrm{kJ} / \mathrm{mol} ; \eta_{c o m}$ is the efficiency of the multistage compressor.

The specific model and process are shown in Figure 2. The setting of simulation parameters:

- The air volume composition is nitrogen $78.12 \%$, oxygen $20.95 \%$, and argon $0.93 \%$ (atmospheric condition is $101.325 \mathrm{kPa}, 0^{\circ} \mathrm{C}$ ).

- The efficiency of the air compressor is set at $85 \%$.

- Molecular sieve switching loss and instrument loss are calculated at $1 \%$ according to Linde's experience.

- The oxygen content of the product is $98 \% \mathrm{O}_{2}$ and $2 \% \mathrm{~N}_{2}$.

- The recycled gas of molecular sieve is $20 \%$ of the processed air, the heating temperature is $120^{\circ} \mathrm{C}$ and the regeneration time is a quarter of the switching period [14].

- Two-stage air compression and two-stage intercooler are used in the air separation unit. 
Table 2. Comparison of the main parameters of the generator set and simulation values under various atmospheres.

\begin{tabular}{|c|c|c|c|c|}
\hline Project & Unit & $\begin{array}{c}\text { The Design Value of } \\
\text { the Conventional } \\
\text { System }\end{array}$ & $\begin{array}{c}\text { Simulation Value of } \\
\text { the Conventional } \\
\text { System }\end{array}$ & $\begin{array}{c}\text { Simulation Value of } \\
\text { OC Power Generation } \\
\text { System }\end{array}$ \\
\hline Rated evaporation & $\mathrm{t} / \mathrm{h}$ & 1760.00 & 1760.00 & 1760.00 \\
\hline Superheated steam pressure & $\mathrm{MPa}$ & 17.29 & 17.29 & 17.29 \\
\hline $\begin{array}{l}\text { Superheated steam } \\
\text { temperature }\end{array}$ & ${ }^{\circ} \mathrm{C}$ & 541.00 & 541.00 & 541.00 \\
\hline Reheat steam flow rate & $\mathrm{t} / \mathrm{h}$ & 1482.00 & $1,482.00$ & 1482.00 \\
\hline Reheat steam inlet pressure & $\mathrm{MPa}$ & 3.46 & 3.46 & 3.46 \\
\hline $\begin{array}{l}\text { Reheat steam inlet } \\
\text { temperature }\end{array}$ & ${ }^{\circ} \mathrm{C}$ & 315.00 & 315.00 & 315.00 \\
\hline Reheat steam outlet pressure & $\mathrm{MPa}$ & 3.28 & 3.28 & 3.28 \\
\hline $\begin{array}{l}\text { Reheat steam outlet } \\
\text { temperature }\end{array}$ & ${ }^{\circ} \mathrm{C}$ & 541.00 & 540.82 & 541.00 \\
\hline Feedwater pressure & $\mathrm{MPa}$ & 18.70 & 18.70 & 18.70 \\
\hline Feed temperature & ${ }^{\circ} \mathrm{C}$ & 272.00 & 271.97 & 271.97 \\
\hline Rated evaporation & $\mathrm{t} / \mathrm{h}$ & 1760.00 & 1760.00 & 1760.00 \\
\hline $\begin{array}{l}\text { Furnace outlet flue gas } \\
\text { temperature }\end{array}$ & ${ }^{\circ} \mathrm{C}$ & $1,134.00$ & $1,135.18$ & $1,157.59$ \\
\hline $\begin{array}{l}\text { Air preheater outlet hot air } \\
\text { temperature }\end{array}$ & ${ }^{\circ} \mathrm{C}$ & 351.00 & 351.00 & - \\
\hline $\begin{array}{l}\text { Gas-gas heat exchanger } \\
\text { outlet hot flue gas } \\
\text { temperature }\end{array}$ & ${ }^{\circ} \mathrm{C}$ & - & - & 351.00 \\
\hline Flue gas temperature & ${ }^{\circ} \mathrm{C}$ & 127.00 & 125.57 & 169.41 \\
\hline Flue gas volume flow rate & $\mathrm{Nm}^{3} / \mathrm{h}$ & $1,692,447.20$ & $1,692,447.20$ & $307,517.40$ \\
\hline Coal consumption quantity & $\mathrm{t} / \mathrm{h}$ & 270.42 & 270.42 & 264.73 \\
\hline Power generation & MW & 600.00 & 600.14 & 600.19 \\
\hline The net plant efficiency & $\%$ & 39.31 & 39.31 & 29.74 \\
\hline
\end{tabular}

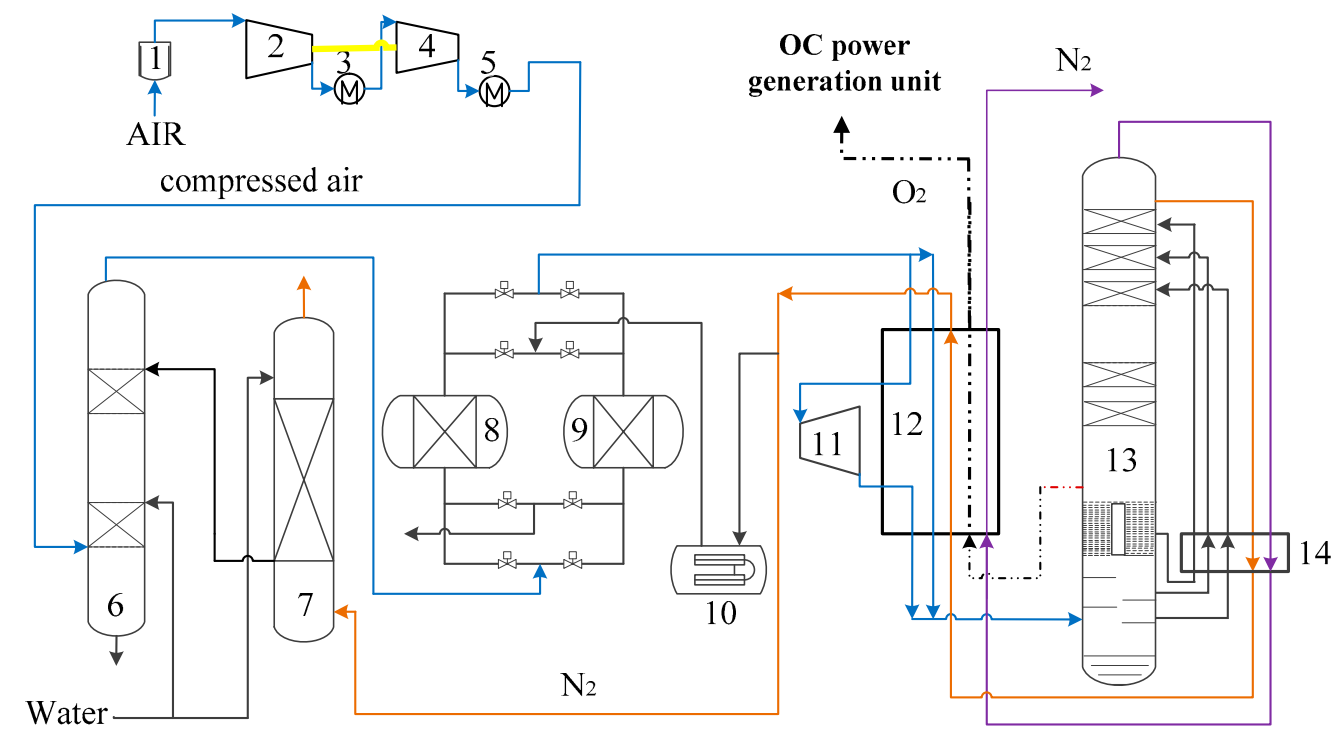

Figure 2. Air separation unit (ASU). Subunits are as follows: 1. Air purification device; 2, 4. Air compressor; 3, 5. Interstage cooler; 6 . Air cooling tower; 7. Water cooling tower; 8, 9. Molecular sieve; 10. Electric heater; 11. Expander; 12. Main heat exchanger; 13. Distillation column; 14. Supercooler.

The above simulation parameters were selected according to the parameters of the air separation unit in [14]. The comparison between the simulated values obtained and those in the literature [14] is shown in Table 3. Table 3 shows that the error between the simulated value in this study and the simulated value in the literature is small, and the energy consumption per unit of oxygen production is approximately $0.36(\mathrm{~kW} \cdot \mathrm{h}) / \mathrm{m}^{3}$, which is basically consistent with the actual production result. 
Thus, verifying the accuracy of the model. Meanwhile, it can be seen that the compression energy consumption of the air separation unit accounts for approximately $97 \%$ of the total energy consumption of the entire air separation unit, the energy consumption of the air separation unit mainly comes from air compression.

Table 3. Air separation unit simulation results.

\begin{tabular}{cccc}
\hline Project & Unit & $\begin{array}{c}\text { Simulation Value in } \\
\text { this Present Study }\end{array}$ & $\begin{array}{c}\text { Simulation Value of } \\
\text { Reference [14] }\end{array}$ \\
\hline Treated air volume & $\mathrm{kmol} / \mathrm{h}$ & $12,766.70$ & $12,735.60$ \\
Loss of air & $\mathrm{kmol} / \mathrm{h}$ & 127.67 & 127.40 \\
Regenerated air capacity & $\mathrm{kmol} / \mathrm{h}$ & 2527.81 & $2,547.10$ \\
Amount of oxygen & $\mathrm{kmol} / \mathrm{h}$ & 2678.60 & 2677.00 \\
Air compressor energy & $\mathrm{kW}$ & $20,958.40$ & $21,230.00$ \\
$\quad$ consumption & $\mathrm{kW}$ & 216.07 & 260.00 \\
$\begin{array}{c}\text { Pump energy consumption } \\
\text { Molecular sieve energy } \\
\text { consumption }\end{array}$ & $\mathrm{kW}$ & 432.13 & 516.00 \\
$\begin{array}{c}\text { Total energy consumption } \\
\text { Energy consumption per unit of } \\
\text { oxygen production }\end{array}$ & $\mathrm{kW}$ & $21,606.60$ & $22,006.00$ \\
\hline
\end{tabular}

\subsubsection{Compressed and Purification Unit of Gas}

Flue gas compression and purification is a process that condenses, purifies, and compresses flue gas until it contains a higher purity of $\mathrm{CO}_{2}$ to meet the requirements of large-scale $\mathrm{CO}_{2}$ transportation. The specific process is that first the $\mathrm{CO}_{2}$ in the flue gas is dehydrated and separated after multistage compression and multistage condensation. Then the flue gas enters the triethylene glycol (TEG) dehydration process for deep dehydration, and finally enters the purification system to separate the entire compressed flue gas flash. After purification, the flue gas is pressurized and heated by a centrifugal pump and heater and transported by a pipe after conforming with the typical conditions of large-scale $\mathrm{CO}_{2}$ transportation. Typical parameters of pipeline transportation are a temperature of $20^{\circ} \mathrm{C}$; a pressure of $11.0 \mathrm{MPa}$, a volume fraction $(\psi)$ of $\mathrm{CO}_{2}$ of greater than $95 \%, \psi\left(\mathrm{O}_{2}, \mathrm{Ar}, \mathrm{N}_{2}\right)$ of less than $4 \%$, and $\psi\left(\mathrm{H}_{2} \mathrm{O}\right)$ of less than $50 \mathrm{ppm}$. A flow diagram of the gas compression and purification unit is shown in Figure 3 [14].

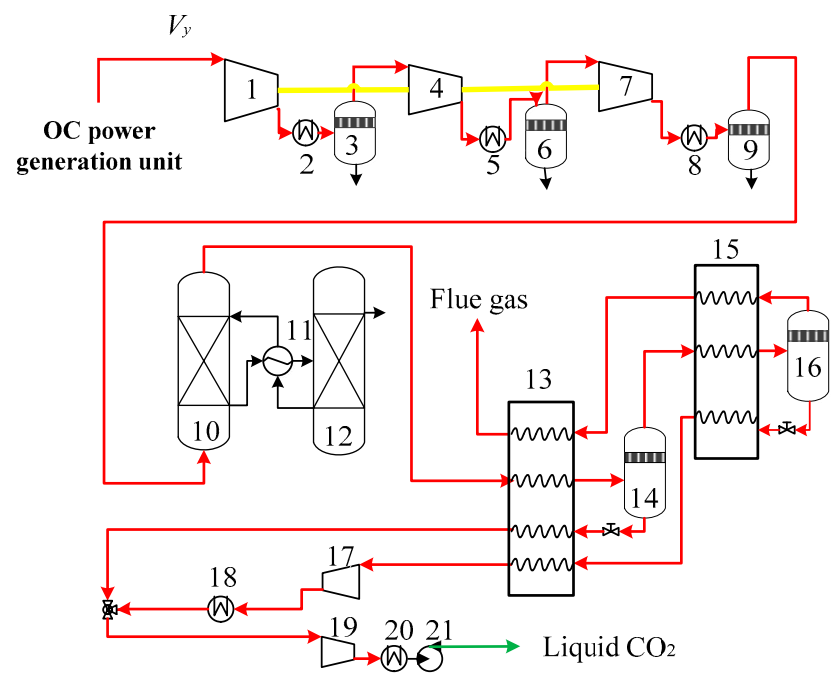

Figure 3. Flue gas compression and purification unit (CPU). Subunits are as follows: 1, 4, 7. Flue gas compressor; 2, 5, 8. Interstage cooler; 3, 6, 9. Interstage dehydrator; 10 . Triethylene glycol absorber; 11. Heat exchanger; 12. Triethylene glycol regeneration tower; 13 . Heat exchanger; 14 . Condenser; 15. Heat exchanger; 16. Condenser; 17. Compressor; 18. Heat exchanger; 19. Compressor; 20. Heat exchanger; 21.Liquid $\mathrm{CO}_{2}$ booster pump. 
The operating energy consumption of the flue gas compression and purification unit can be calculated by the electrical power $E_{\mathrm{CPU}}$ required to compress the flue gas with a flow rate of $V_{y}$ and the highly pure $\mathrm{CO}_{2}$ in the flue gas.

According to the calculation model of compression work $W^{0}$ of the actual gas theory, the calculation model of operation energy consumption of $\mathrm{CO}_{2}$ compression and purification unit can be obtained as:

$$
E_{\mathrm{CPU}}=\frac{\sum\left(\varphi_{y-e} \sum_{i}^{n} W_{i,(y-e)}^{0}\right) V_{y}+\sum_{q}^{n}\left(W_{q, \mathrm{CO}_{2}}^{0} V_{q, \mathrm{CO}_{2}}\right)}{22.4 \eta_{c o m}}+\frac{W_{p, \mathrm{CO}_{2}}^{0} V_{\mathrm{CO}_{2}}}{22.4 \eta_{p}}
$$

where $\varphi_{y-e}$ is the portion of $e$ gas contained in the flue gas; $W_{i,(y-e)}^{0}$ is the theoretical compression work required for adiabatic compression of $e$ gas in the smoke by the $n$th stage of the multistage compressor, $\mathrm{kJ} / \mathrm{mol} ; V_{y}$ is the gas flow rate into the multi-stage compressor, $\mathrm{m}^{3} / \mathrm{s} ; W_{q, \mathrm{CO}_{2}}^{0}$ is the theoretical compression work required for adiabatic compression of $\mathrm{CO}_{2}$ by the $q$-class multi-stage compressor, $\mathrm{kJ} / \mathrm{mol} ; V_{q, \mathrm{CO}_{2}}$ is the $q$ th stage $\mathrm{CO}_{2}$ flow rate into the multi-stage compressor, $\mathrm{m} / \mathrm{s} ; \eta_{\text {com }}$ is the efficiency of multi-stage compressor; $W_{p, \mathrm{CO}_{2}}^{0}$ is the theoretical compression work required for the adiabatic compression of liquid $\mathrm{CO}_{2}$ by the booster pump, $\mathrm{kJ} / \mathrm{mol} ; V_{\mathrm{CO}_{2}}$ is the $\mathrm{CO}_{2}$ flow into the booster pump, $\mathrm{m}^{3} / \mathrm{s} ; \eta_{p}$ is the efficiency of booster pump.

\subsection{Calculation Model of Energy Consumption of the Oxyfuel System}

A calculation model of the net standard coal consumption rate of the OC power generation system is

$$
\begin{gathered}
L_{f c y}=\frac{W_{d}}{W_{f}} \times 100 \\
b_{f}=\frac{B_{b}}{W_{f}} \\
b_{g}=\frac{b_{f}}{1-\frac{L_{f c y}}{100}} \\
\eta=\frac{3600\left(W_{f}-W_{d}\right)}{B \cdot Q} \\
\mathrm{EP}=1-\frac{\eta_{O C}}{\eta_{r e f}}
\end{gathered}
$$

where $W_{d}$ is the power consumption of the plant, $\mathrm{kW} ; W_{f}$ is the power generation, $\mathrm{kW} ; L_{f c y}$ is the auxiliary power ratio, $\%$; $B$ is the coal consumption, $\mathrm{kg} / \mathrm{h} ; B_{b}$ is the standard coal consumption, $\mathrm{kg} / \mathrm{h} ; b_{f}$ is the gross coal consumption rate, $\mathrm{g} / \mathrm{kWh}$; and $b_{g}$ is the net standard coal consumption rate, $\mathrm{g} / \mathrm{kWh}$. $\eta$ is the net electrical efficiency; EP is the energy penalty due to carbon capture in an OC power generation system, $\% ; Q$ is the low heating value of coal, $\mathrm{kJ} / \mathrm{kg} ; \eta_{o c}$ is the net electrical efficiency of the OC power generation system; $\eta_{r e f}$ is the net electrical efficiencies of the reference plant.

\section{Results and Discussion}

The net standard coal consumption rate and the net electrical efficiency of an OC power generation system were the important energy consumption indicators in its operation. In this study, flow models of the entire conventional and OC power generation systems were made. On the basis of the literature $[10,14,15,19]$, as influencing factors, we selected four key operating parameters: oxygen purity $\left(\varphi_{\mathrm{O}_{2}}\right)$, oxygen concentration $\left(r_{\mathrm{O}_{2}}\right)$, recirculation rate of dry flue gas in boiler flue gas $\left(\chi_{1}\right)$, and the excess oxygen coefficient $\left(\alpha_{\mathrm{O}_{2}}\right)$. The single-factor and multifactor orthogonal influences of the above four operating parameters on the net standard coal consumption rate and the net electrical efficiency 
were analyzed. Other factors in the process of analysis, whether variable or immutable, were taken as input to known conditions.

\subsection{Operating Factors Influencing Energy Consumption of an Oxyfuel Combustion System}

\subsubsection{Oxygen purity $\left(\varphi_{\mathrm{O}_{2}}\right)$}

Figure 4 shows that with the increased oxygen purity $\left(\varphi_{\mathrm{O}_{2}}\right)$, the oxygen flow rate into the boiler for combustion and the flue gas volume into the CPU all decreased. Energy consumption per unit of oxygen production and the air separation system increased.

It can be explained as follows: With the increase of $\varphi_{\mathrm{O}_{2}}$, the actual separation work $W_{s}$ required by the air separation process and the flow pressure required by the compressed air will both increase, resulting in the corresponding increase in the oxygen mono consumption; other things being equal, the oxygen flow rate $V_{\mathrm{O}_{2}}$ (Figure 1) decreases as the oxygen purity increases. Although the oxygen flow decreased somewhat, it was not enough to offset the effects of increased energy consumption per unit of oxygen production, so the energy consumption of ASU increased with the increase of oxygen purity.

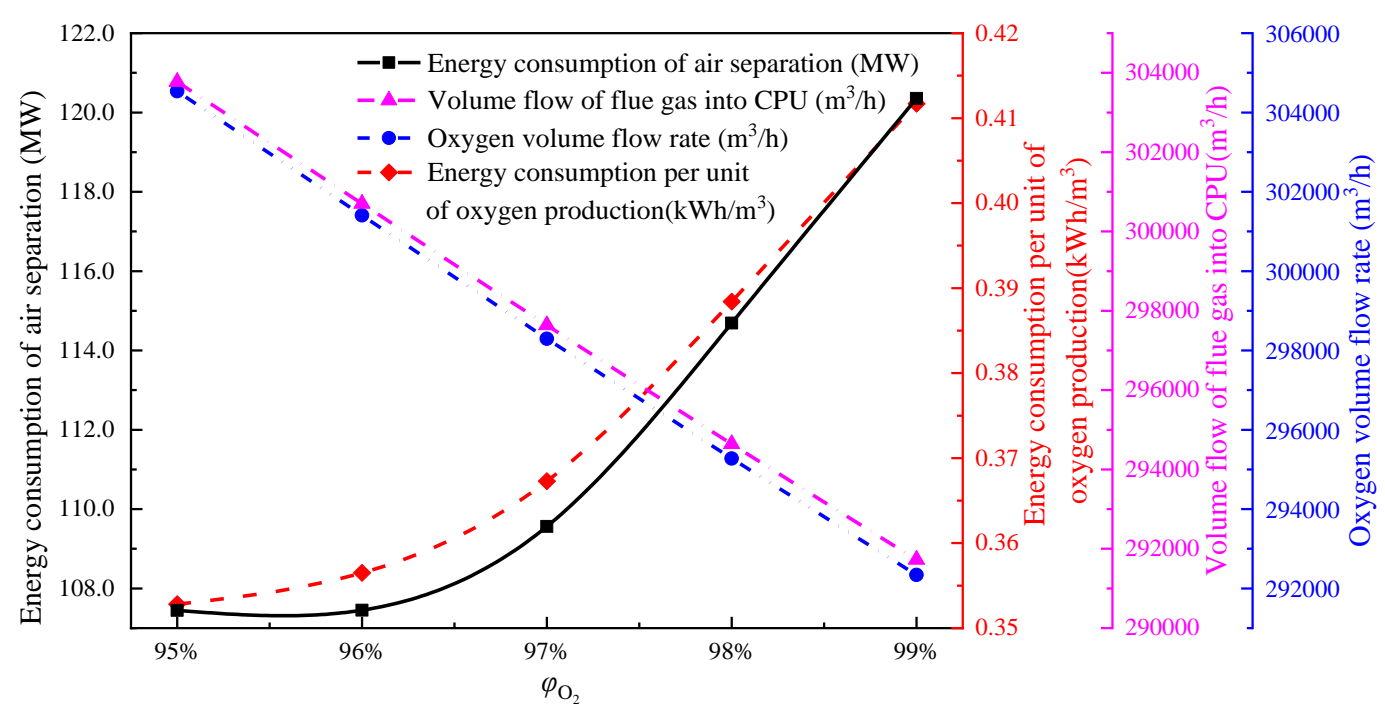

Figure 4. Energy consumption per unit of oxygen production, volume flow of flue gas into CPU, oxygen volume flow rate, the energy consumption of air separation for various $\varphi_{\mathrm{O}_{2}}$.

As the oxygen purity increases, the oxygen flows into the boiler for combustion to decrease. Under the premise of constant oxygen concentration, the amount of circulating flue gas ( $V_{r f}$, see Equation (3)) increases correspondingly to supplement the influence brought by the decrease of oxygen quantity, which leads to the increase of power consumption of the circulating fan. At the same time, the total amount of flue gas $\left(V_{f g}\right.$, see Figure 1$)$ increases due to the increase of circulating flue gas flow $\left(V_{r f}\right.$, see Equation (3)). The increase of $V_{f g}$ leads to the decrease of flue gas temperature difference under the condition of the same heat transfer, which leads to the rise of flue gas temperature. However, due to the rising of the flue gas temperature, the heat loss of the flue gas was increased, resulting in the decrease of boiler efficiency and the increase of boiler coal consumption, but the range is not large. Due to the increase of $V_{r f}$, although $V_{f g}$ increases, it will still lead to a decrease in flue gas flow ( $V_{y}$, see Figure 1 ). As $V_{y}$ decreases, the amount of flue gas entering the CPU unit decreases. According to Equation (9), $V_{y}$ decreases and $E_{C P U}$ decreases, so the energy consumption of the flue gas compression unit decreases.

Figure 5 shows that the energy consumption of the ASU increases with the increase of oxygen purity, and the increased range becomes larger when the purity is higher than $96 \%$. The energy consumption of CPU decreases with the increase of oxygen purity, but the decrease is small. The power consumption of the circulating fan also increases correspondingly. The superposition of the above 
effects causes the total energy consumption of the system to decrease first and then increase with the increase of oxygen purity, which was the minimum when the oxygen purity was $96 \%$.

Figure 6 shows that with the increase of oxygen purity, the system's power supply and the net electrical efficiency first increased and then decreased, and reached the maximum when the oxygen purity was $96 \%$. The net standard coal consumption rate and the energy penalty due to carbon capture in an OC power generation system (EP) decrease first and then increase, and were minimized when the purity was $96 \%$.

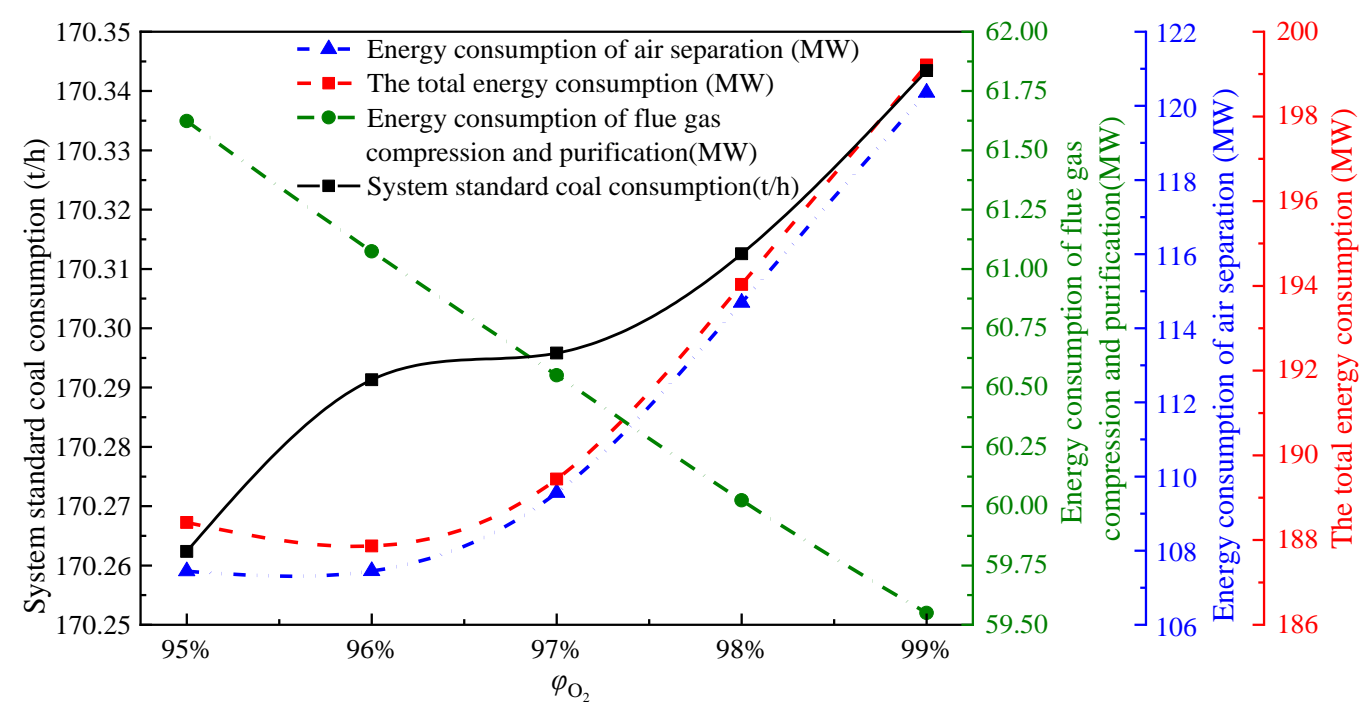

Figure 5. Energy consumption of the air separation, the flue gas compression and purification, and the total system, coal consumption for various $\varphi_{\mathrm{O}_{2}}$.

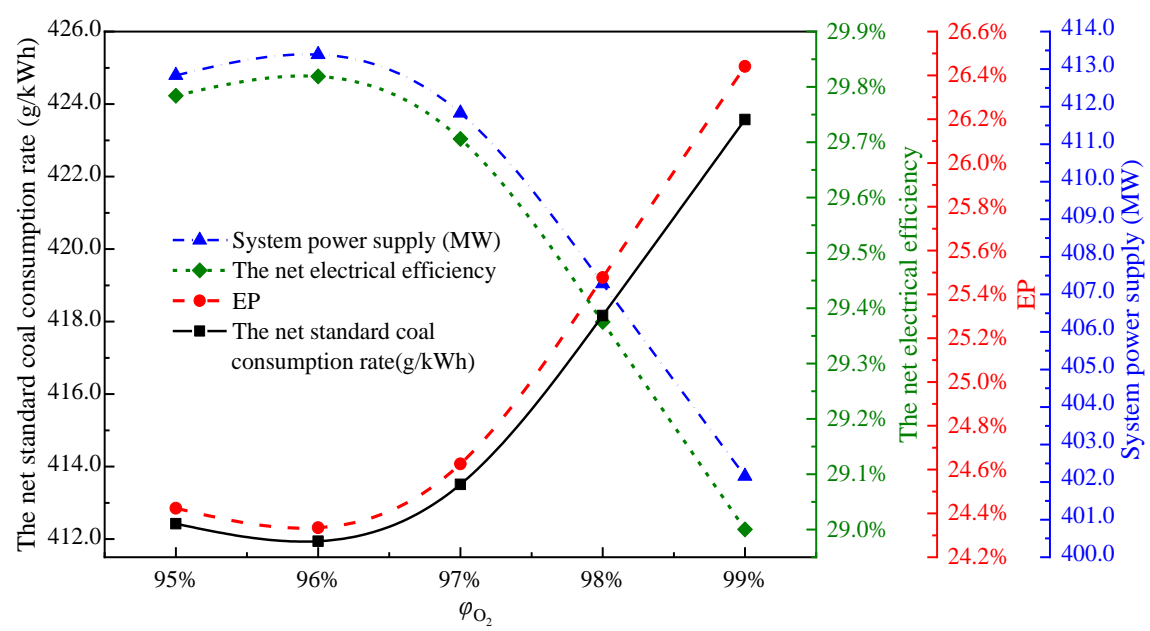

Figure 6. System power supply, the net electrical efficiency, the energy penalty due to carbon capture in an $\mathrm{OC}$ power generation system (EP), and the net standard coal consumption rate of the system for various $\varphi_{\mathrm{O}_{2}}$.

\subsubsection{Oxygen Concentrations $\left(r_{\mathrm{O}_{2}}\right)$}

Figure 7 shows that the temperature of high-temperature flue gas entering the flue gas preheater decreased with the increase in oxygen concentration, and the temperature of primary flue gas requiring preheating was $351{ }^{\circ} \mathrm{C}$. When the oxygen concentration reached $33.4 \%$, the flue gas temperature was equal to that of the required preheating primary flue gas. Therefore, we selected the range of oxygen concentrations like $21 \%$ to $33 \%$. It can be explained as follows: with the increase of oxygen concentration, the decrease of flue gas volume $\left(V_{r f}\right.$, see Equation (3)) leads to the increase 
of flue gas temperature difference when the heat transfer in the furnace is constant, so the flue gas temperature decreases.

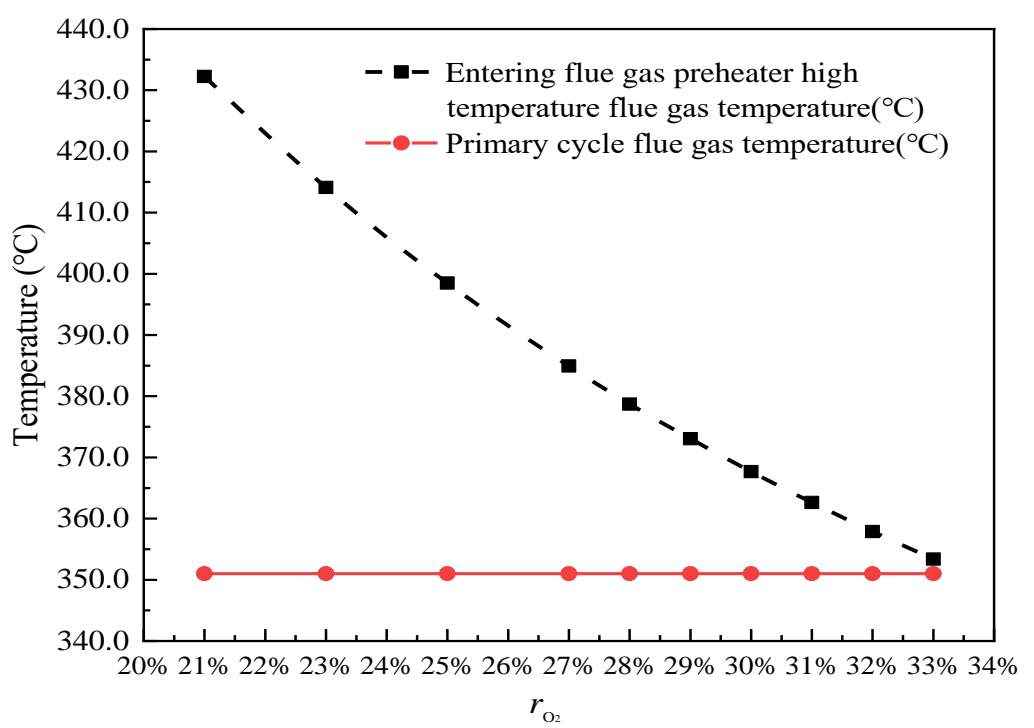

Figure 7. The relation between the temperature of flue gas in the primary cycle and the temperature of flue gas entering the gas-gas heat exchanger for various $r_{\mathrm{O}_{2}}$.

Figure 8 shows that energy consumption of ASU, energy consumption of CPU, the total energy consumption of the system, and the system standard coal consumption all decrease with the increase of oxygen concentration.

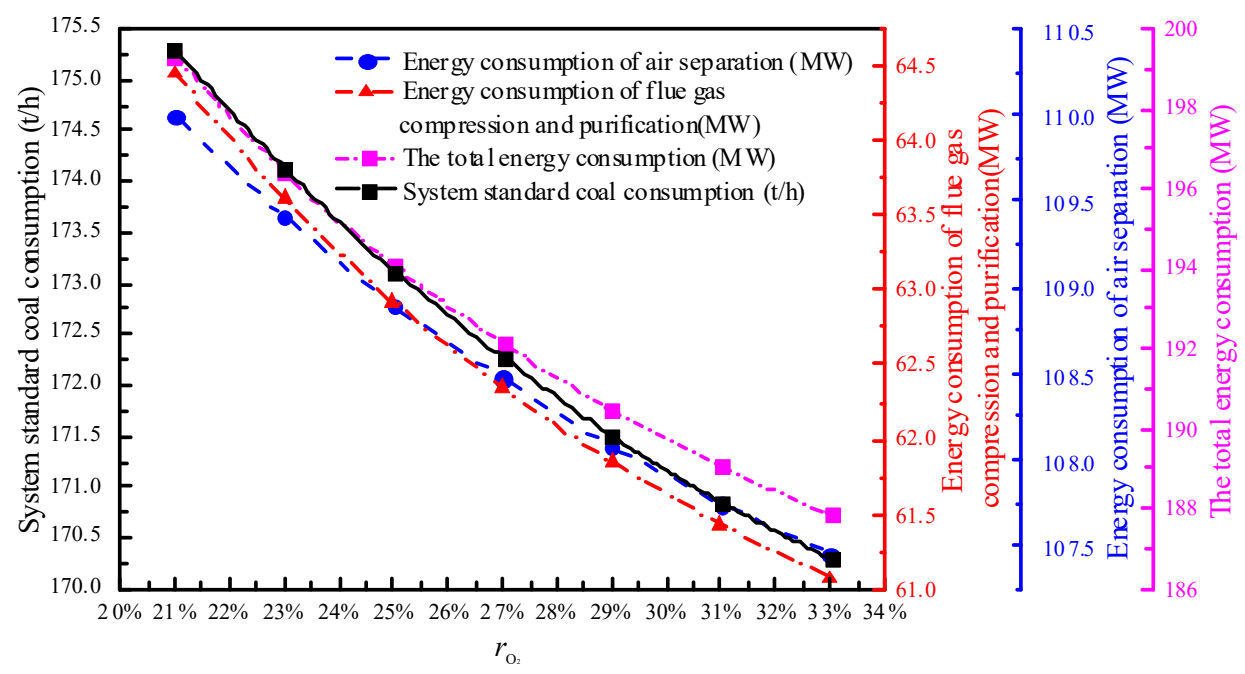

Figure 8. Energy consumption of air separation, compression and purification of flue gas, system total energy consumption, and the system standard coal consumption for various $r_{\mathrm{O}_{2}}$.

It can be explained as follows: with the increase of oxygen concentration, the coal burnout rate increases, resulting in the reduction of oxygen required for combustion $\left(V_{\mathrm{O}_{2}}\right.$, see Figure 1$)$, resulting in the reduction of energy consumption of the ASU; after the oxygen concentration rises, the amount of other gases into the air decreases, thus reducing the amount of circulating flue gas ( $V_{r f}$, see Equation (3)) and the power consumption of the circulating fan. At the same time, the flue gas volume of the system ( $V_{y}$, see Figure 1$)$ is also reduced, thus reducing the energy consumption of the CPU. Above all, the total energy consumption of the system decreases, and the power supply of the system increases. However, due to the constant total heat release, the decrease of flue gas volume $\left(V_{f g}\right.$, see Figure 1$)$ leads to the 
increase of flue gas temperature difference, so the flue gas temperature decreases. The flue gas volume $\left(V_{f g 1}\right.$, see Figure 1$)$ and the flue gas temperature of the system was reduced, so the heat loss of the system flue is reduced, the thermal efficiency of the boiler is increased, and the coal consumption of the system is reduced.

Figure 9 shows that with the increase of oxygen concentration, the system power supply and the net electrical efficiency of the system increase, the net standard coal consumption rate and the energy penalty due to carbon capture in an OC power generation system (EP) reduce. It can be explained as follows: the external power supply of the system remains unchanged, while the power consumption of the plant decreases, so the external power output increases; At the same time, as the coal consumption decreases, the net standard coal consumption rate decreases, the net electrical efficiency increases, and the EP decreases.

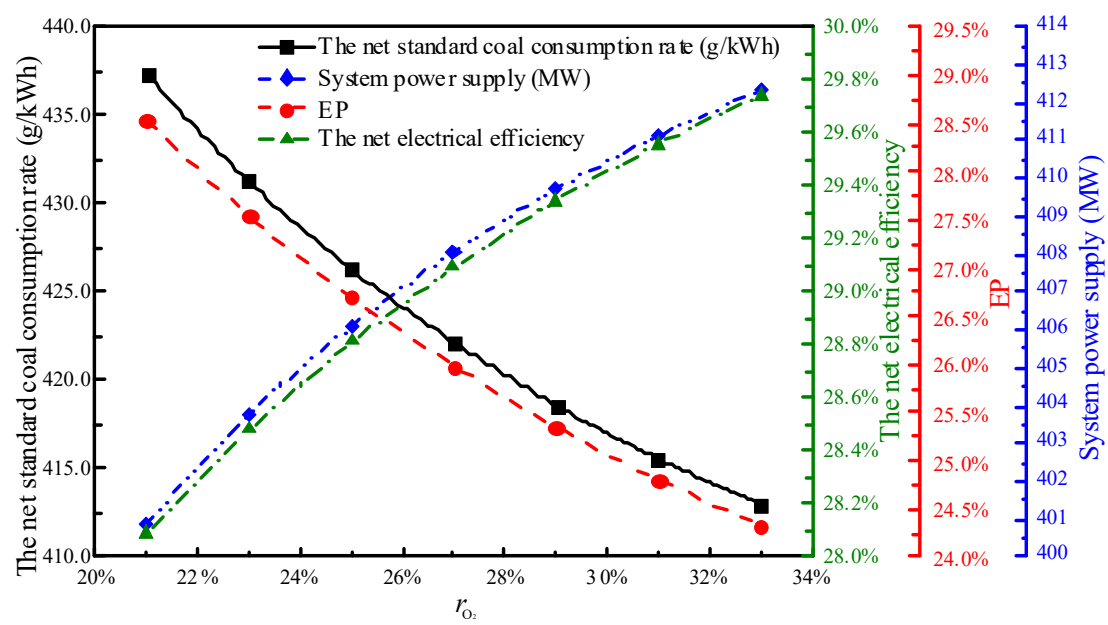

Figure 9. System power supply, the net electrical efficiency, the energy penalty due to carbon capture in an OC power generation system (EP), and the net standard coal consumption rate of the system for various $r_{\mathrm{O}_{2}}$.

\subsubsection{The recirculation Rate of Dry Flue Gas in Boiler Flue Gas $\left(\chi_{1}\right)$}

$\chi_{1}$ is the recirculation rate of dry flue gas in the boiler flue gas. Figure 10 shows that with the increase in $\chi_{1}$, the total amount of flue gas discharged decreased. However, as the $\mathrm{CO}_{2}$ content in the flue gas increased, the total $\mathrm{CO}_{2}$ in the flue gas increased. Therefore, if the capture rate remained unchanged, the amount of $\mathrm{CO}_{2}$ that must be collected and compressed increased.

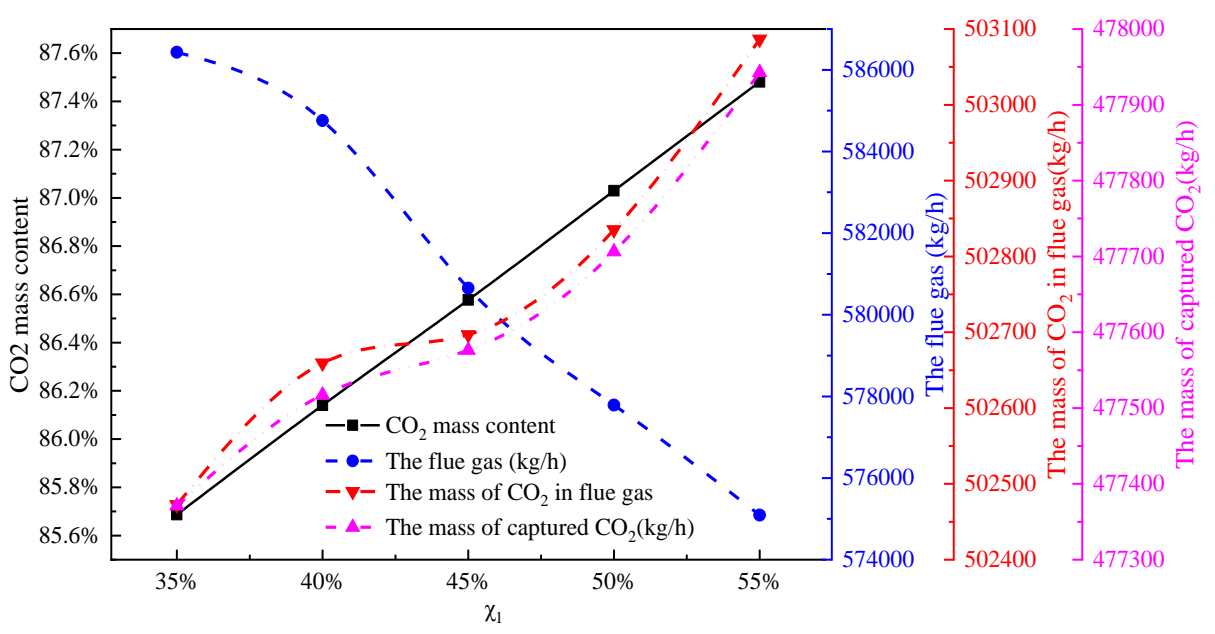

Figure 10. Trend chart of flue gas quality, $\mathrm{CO}_{2}$ content in flue gas, total $\mathrm{CO}_{2}$ mass in flue gas, and $\mathrm{CO}_{2}$ capture mass for various $\chi_{1}$. 
Figure 11 shows that with the increase of $\chi_{1}$, the energy consumption of the ASU, the energy consumption of the CPU and the total energy consumption of the system decrease, while the standard coal consumption of the system increases.

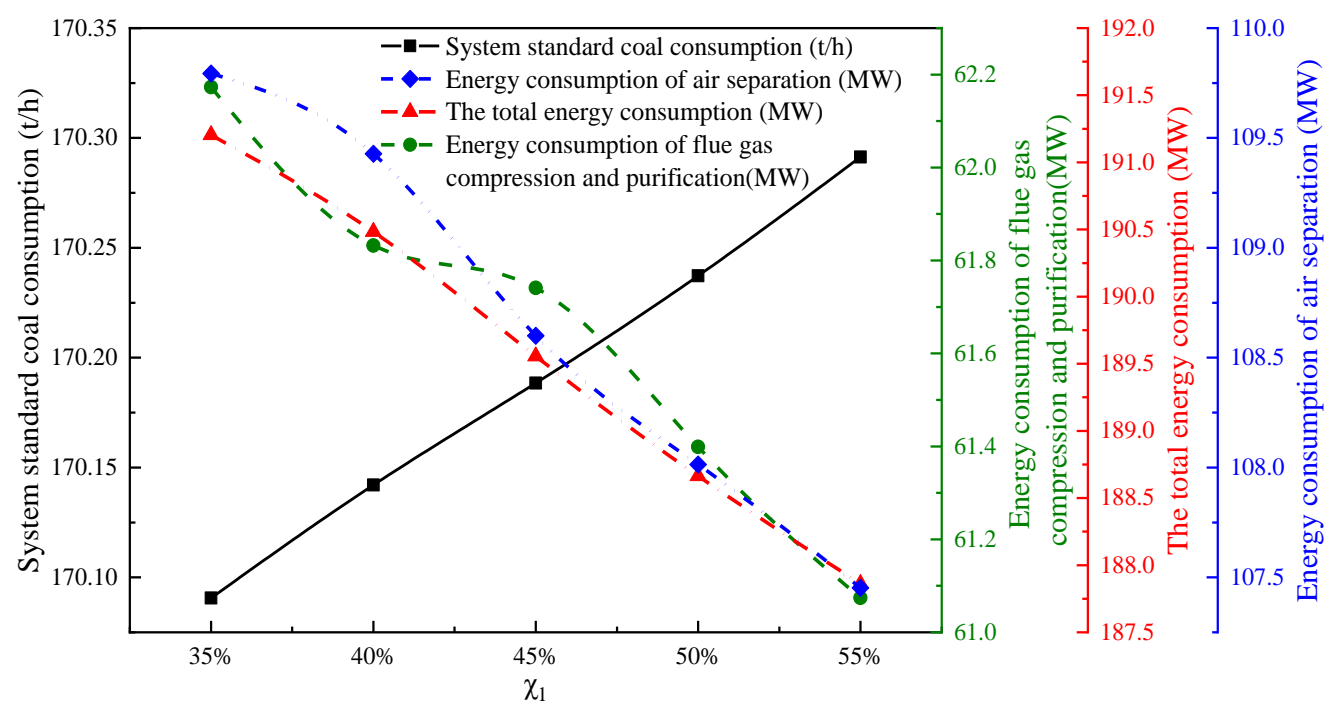

Figure 11. System standard coal consumption, the energy consumption of air separation, compression and purification of flue gas, and system total energy consumption for various $\left(\chi_{1}\right)$.

It can be explained as follows: with the increase of $\chi_{1}$, the higher oxygen content of the primary flue gas after dehydration reduces the amount of oxygen supplied $\left(V_{\mathrm{O}_{2}}\right.$, see Figure 1$)$. The energy consumption of the ASU was also reduced as the amount of oxygen supplied reduced. However, due to the increase in $\chi_{1}$, the amount of secondary flue gas circulation $\left(V_{r f}^{w}\right.$, see Figure 1$)$ decreases, and because the oxygen content of primary flue gas $\left(V_{r f}^{d}\right.$, see Figure 1$)$ after dehydration is higher, when the oxygen concentration remains unchanged, the amount of secondary flue gas reduction will be higher than the amount of primary flue gas increment, so the total flue gas circulation rate will be reduced, and the power consumption of circulating fan will be correspondingly reduced. However, due to the increase of the primary flue gas circulation, the flue gas output $\left(V_{f g}\right.$, see Figure 1 ) of the system increases. With the increase of $V_{f g 2}$, when the discharge heat of flue gas was unchanged, the temperature difference of flue gas decreased, so the flue gas temperature rises. As a result, the heat loss of flue gas increased, the boiler efficiency decreased, and the boiler coal consumption increased. At the same time, the energy consumption of gas compression and purification was reduced due to the increase of primary gas circulation and the decrease of $\left(V_{f g}\right.$, see Figure 1$)$. The above effects added up to reduce the total energy consumption of the system.

Figure 12 shows that with the increase in $\chi_{1}$, the power supply of the OC power generation system and the net electrical efficiency showed an increasing trend, whereas the net coal consumption of the system and the energy penalty due to carbon capture in an OC power generation system (EP) showed a decreasing trend.

It can be explained as follows: with the increase of $\chi_{1}$, the energy consumption of the ASU and the energy consumption of the CPU all reduced. The boiler coal consumption increased with the increase of $\chi_{1}$, but the increased range was small. These effects added up to the above results. 


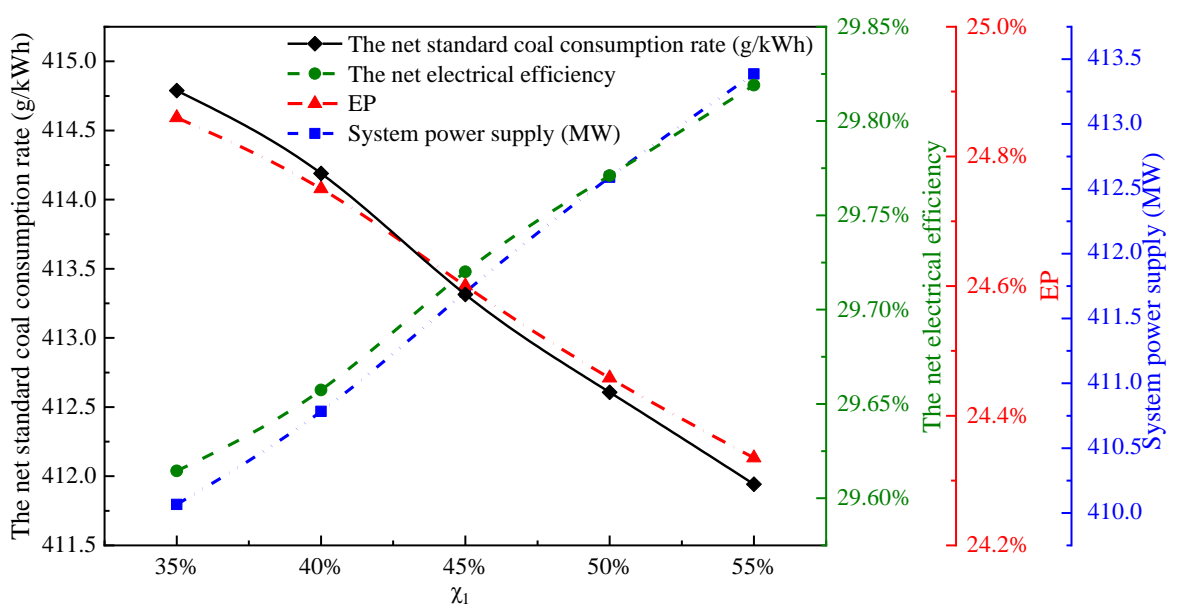

Figure 12. The net standard coal consumption rate, the net electrical efficiency, the energy penalty due to carbon capture in an OC power generation system (EP), and the power supply of the system for various $\chi_{1}$.

\subsubsection{Excess Oxygen Coefficient $\left(\alpha_{\mathrm{O}_{2}}\right)$}

Figure 13 shows that with the increase of $\alpha_{\mathrm{O}_{2}}$, energy consumption of the air separation system, gas compression system, total energy consumption, and standard coal consumption of the system increase.

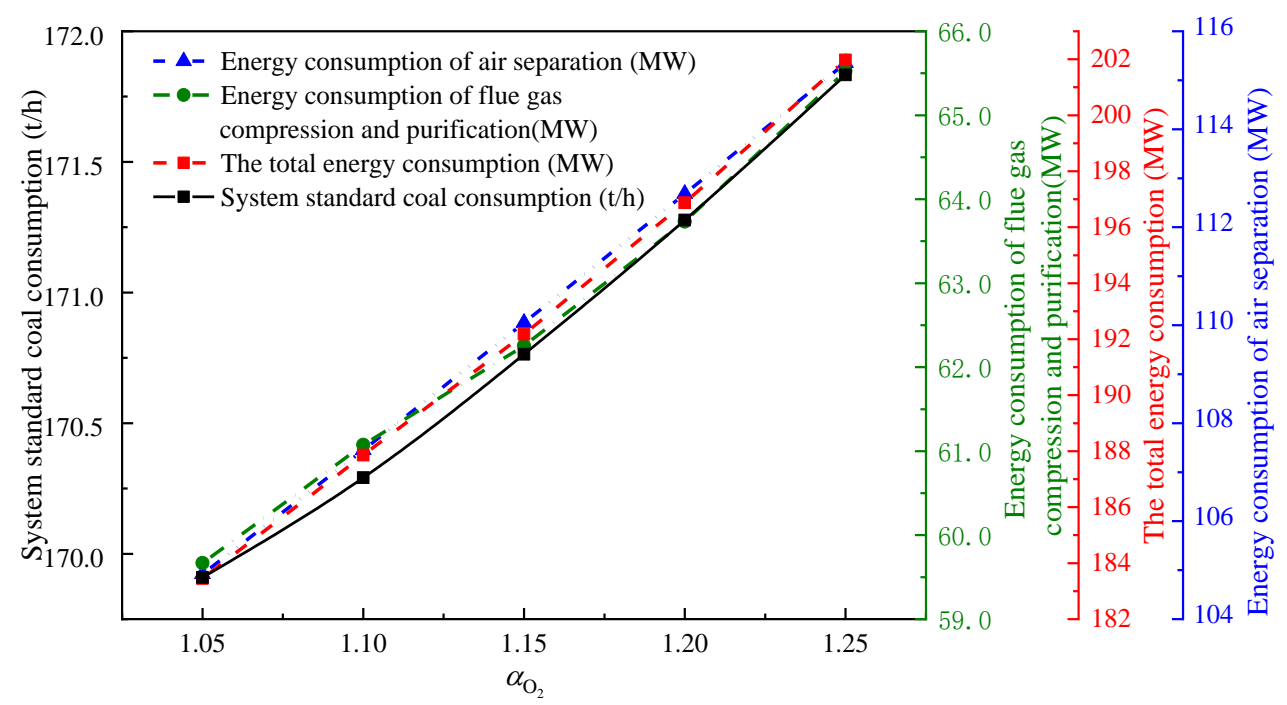

Figure 13. Energy consumption of air separation, the energy consumption of flue gas compression and purification, the total energy consumption, and system standard coal consumption for various $\alpha_{\mathrm{O}_{2}}$.

It can be explained as follows: with the increase of excess oxygen coefficient, the amount of oxygen supplied $\left(V_{\mathrm{O}_{2}}\right.$, see Figure 1$)$ increases, and when the single consumption of oxygen production remains unchanged, the energy consumption of the air separation system increases. Moreover, due to the increase of oxygen supply, the amount of flue gas $\left(V_{f g}\right.$, see Figure 1$)$ increases, so the amount of circulating flue gas $\left(V_{r f}\right.$, see Equation (3)) and the amount of flue gas $\left(V_{y}\right.$, see Figure 1$)$ also increase correspondingly. The increase of $V_{r f}$ leads to the increase of power consumption of the circulating fan, and the increase of $V_{y}$ leads to an increase of CPU energy consumption. When $V_{f g}$ increased, the temperature difference of flue gas decreased when the heat transfer of flue gas was constant, so the flue gas temperature increased. Above all, the total energy consumption of the system increased. At the same time, the increase of flue gas volume led to an increase in, heat loss and coal consumption.

Figure 14 shows that with the increase of the excess oxygen coefficient, the system power supply, and the net electrical efficiency decreased, and the net standard coal consumption rate and the energy 
penalty due to carbon capture in an OC power generation system (EP) increased. The power generation of the system remained unchanged, while the total energy consumption of the system increased, so the external output power decreased; at the same time, due to the increase of coal consumption, the net standard coal consumption rate increased, the net electrical efficiency decreased, and the net electrical efficiency drop increased.

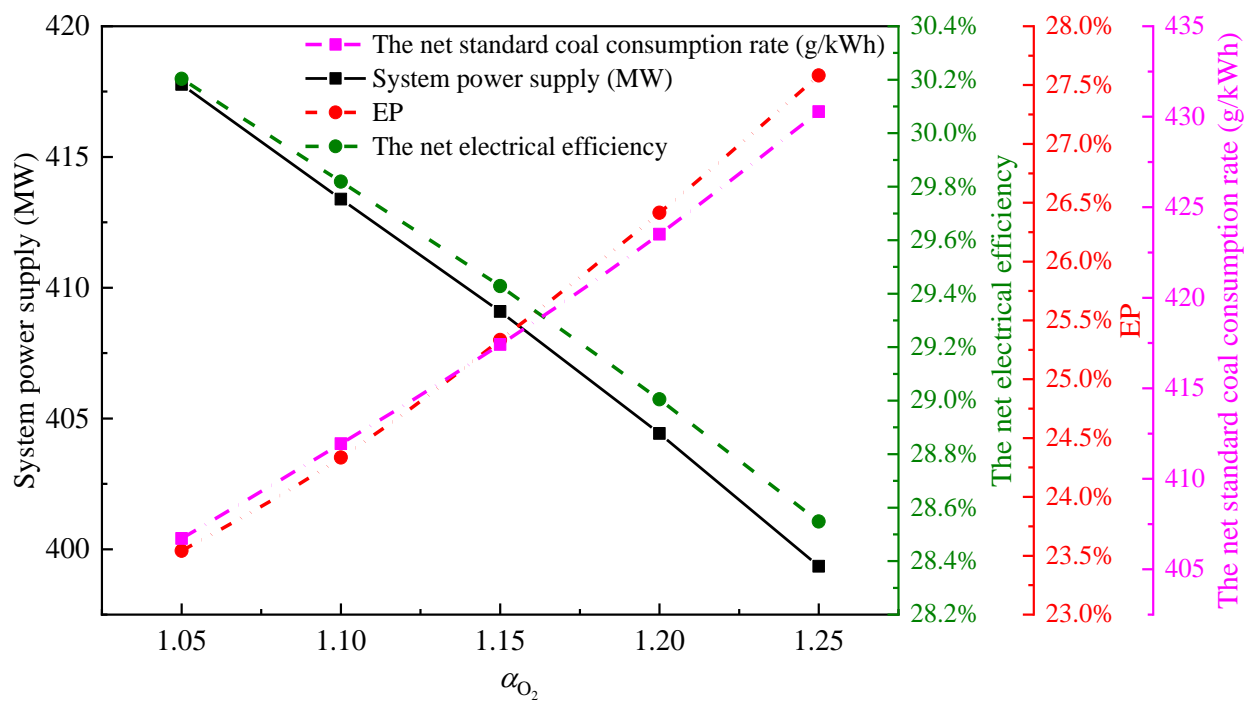

Figure 14. The net standard coal consumption rate, system power supply, the net electrical efficiency, and the energy penalty due to carbon capture in an OC power generation system (EP) for various $\alpha_{\mathrm{O}_{2}}$.

Based on the above results, it can be seen that when the oxygen purity $\left(\varphi_{\mathrm{O}_{2}}\right)$ increased, the oxygen concentration $\left(r_{\mathrm{O}_{2}}\right)$ decreased, the recirculation rate of dry flue gas in boiler flue gas $\left(\chi_{1}\right)$ decreased and the excess oxygen coefficient $\left(\alpha_{\mathrm{O}_{2}}\right)$ increased, the power supply standard coal consumption of the OC power generation system increased and the net power efficiency of the system decreased. When oxygen purity, oxygen concentration, the recirculation rate of dry flue gas in boiler flue gas, and excess oxygen coefficient were $96 \%, 33 \%, 55 \%$, and 1.05 , respectively, the net standard coal consumption rate of system was minimum, and the net electrical efficiency of the system was maximum.

\subsection{Orthogonal Analysis of the Influence of Operating Factors on Energy Consumption of the Oxyfuel Combustion System}

The orthogonal analysis test method can consider the individual effect of each key parameter on system performance. It can also consider the influence of the interaction between factors on system performance.

\subsubsection{Orthogonal Experimental Design}

On the basis of the results of the single-factor study above, we selected four parameters as factors: oxygen purity $\left(\varphi_{\mathrm{O}_{2}}\right)$, oxygen concentration $\left(r_{\mathrm{O}_{2}}\right)$, the recirculation rate of dry flue gas in boiler flue gas $\left(\chi_{1}\right)$, and the excess oxygen coefficient $\left(\alpha_{\mathrm{O}_{2}}\right)$. We then used five levels of each factor to design the orthogonal test. The $\mathrm{L}_{25}\left(5^{6}\right)$ orthogonal table was used, with four factors accounting for one column each. The remaining two columns were left blank for error analysis. See Table 4 for the specific experimental design. 
Table 4. Factors and levels of the orthogonal test.

\begin{tabular}{ccccc}
\hline \multirow{2}{*}{ Level } & \multicolumn{4}{c}{ Factors } \\
\cline { 2 - 5 } & $\boldsymbol{\varphi}_{\mathrm{O}_{2}} \mathbf{A}(\%)$ & $\boldsymbol{r}_{\boldsymbol{O}_{2}} \mathbf{B}(\%)$ & $\chi_{1} \mathbf{C}(\%)$ & $\alpha_{\boldsymbol{O}_{2}} \mathbf{D}$ \\
\hline 1 & 95.0 & 25.0 & 35.0 & 1.05 \\
2 & 96.0 & 27.0 & 40.0 & 1.10 \\
3 & 97.0 & 29.0 & 45.0 & 1.15 \\
4 & 98.0 & 31.0 & 50.0 & 1.20 \\
5 & 99.0 & 33.0 & 55.0 & 1.25 \\
\hline
\end{tabular}

\subsubsection{Orthogonal Test Scheme and Experimental Results}

The orthogonal test scheme and results are shown in Table 5.

Table 5. Orthogonal test scheme and results.

\begin{tabular}{|c|c|c|c|c|c|c|c|c|}
\hline $\begin{array}{l}\text { Trial } \\
\text { No. }\end{array}$ & $\begin{array}{c}\varphi_{O_{2}} \\
\mathbf{A}(\%)\end{array}$ & $\begin{array}{c}r_{\mathrm{O} 2} \\
\text { B (\%) }\end{array}$ & $\chi_{1}$ C (\%) & $\begin{array}{c}\alpha_{\mathrm{O}_{2}} \\
\mathbf{D}\end{array}$ & Error 1 & Error 2 & $\begin{array}{c}\text { Net Standard Coal } \\
\text { Consumption Rate } \\
(\mathrm{g} / \mathrm{kWh})\end{array}$ & $\begin{array}{l}\text { Net Electrical } \\
\text { Efficiency (\%) }\end{array}$ \\
\hline 1 & 95.0 & 25.0 & 35.0 & 1.05 & 1 & 1 & 419.33 & 29.29 \\
\hline 2 & 95.0 & 27.0 & 40.0 & 1.10 & 2 & 2 & 423.93 & 28.98 \\
\hline 3 & 95.0 & 29.0 & 45.0 & 1.15 & 3 & 3 & 427.66 & 28.72 \\
\hline 4 & 95.0 & 31.0 & 50.0 & 1.20 & 4 & 4 & 430.68 & 28.52 \\
\hline 5 & 95.0 & 33.0 & 55.0 & 1.25 & 5 & 5 & 434.13 & 28.30 \\
\hline 6 & 96.0 & 25.0 & 40.0 & 1.15 & 4 & 5 & 437.61 & 28.07 \\
\hline 7 & 96.0 & 27.0 & 45.0 & 1.20 & 5 & 1 & 441.01 & 27.85 \\
\hline 8 & 96.0 & 29.0 & 50.0 & 1.25 & 1 & 2 & 442.31 & 27.77 \\
\hline 9 & 96.0 & 31.0 & 55.0 & 1.05 & 2 & 3 & 409.75 & 29.98 \\
\hline 10 & 96.0 & 33.0 & 35.0 & 1.10 & 3 & 4 & 415.97 & 29.53 \\
\hline 11 & 97.0 & 25.0 & 45.0 & 1.25 & 2 & 4 & 459.89 & 26.71 \\
\hline 12 & 97.0 & 27.0 & 50.0 & 1.05 & 3 & 5 & 416.82 & 29.47 \\
\hline 13 & 97.0 & 29.0 & 55.0 & 1.10 & 4 & 1 & 419.88 & 29.26 \\
\hline 14 & 97.0 & 31.0 & 35.0 & 1.15 & 5 & 2 & 427.73 & 28.72 \\
\hline 15 & 97.0 & 33.0 & 40.0 & 1.20 & 1 & 3 & 431.75 & 28.45 \\
\hline 16 & 98.0 & 25.0 & 50.0 & 1.10 & 5 & 3 & 432.62 & 28.39 \\
\hline 17 & 98.0 & 27.0 & 55.0 & 1.15 & 1 & 4 & 429.21 & 28.62 \\
\hline 18 & 98.0 & 29.0 & 35.0 & 1.20 & 2 & 5 & 446.94 & 27.48 \\
\hline 19 & 98.0 & 31.0 & 40.0 & 1.25 & 3 & 1 & 450.29 & 27.28 \\
\hline 20 & 98.0 & 33.0 & 45.0 & 1.05 & 4 & 3 & 413.69 & 29.69 \\
\hline 21 & 99.0 & 25.0 & 55.0 & 1.20 & 3 & 2 & 466.87 & 26.31 \\
\hline 22 & 99.0 & 27.0 & 35.0 & 1.25 & 4 & 3 & 471.37 & 26.06 \\
\hline 23 & 99.0 & 29.0 & 40.0 & 1.05 & 5 & 4 & 423.68 & 28.99 \\
\hline 24 & 99.0 & 31.0 & 45.0 & 1.10 & 1 & 5 & 428.42 & 28.67 \\
\hline 25 & 99.0 & 33.0 & 50.0 & 1.15 & 2 & 1 & 432.13 & 28.43 \\
\hline
\end{tabular}

\subsubsection{Orthogonal Test Range Analysis}

On the basis of the test designed by the orthogonal table, we calculated the index value of each test and judged the sensitivity of each factor to the index according to the test result:

$$
\overline{k_{i j}}=\frac{1}{S} K_{i j}
$$

where $K_{i j}$ is the sum of the test results with the horizontal sign $i$ on the column $j, \overline{k_{i j}}$ is the factor in the $j$ column and the mean value of orthogonal test results at horizontal $i$, and $S$ is the number of occurrences of horizontal $i$ on the $j$ column.

The evaluation criterion for the factor sensitivity of the range analysis method is $R_{j} . R_{j}$ is the difference between the $\overline{k_{i j}}$ maximum and minimum values of the statistical parameters calculated at each level of the factor. The formula is as follows:

$$
R_{j}=\max \left(\overline{k_{i j}}\right)-\min \left(\overline{k_{i j}}\right)
$$


The range reflects the relative influence of each factor on the test index. The influence degree of factors can be directly judged from $R$. The greater the range $R$, the greater the influence of the factor level on the net standard coal consumption rate of the OC power generation system.

Tables 6 and 7, and Figure 15 show that in the orthogonal test analysis of the net standard coal consumption rate of $\mathrm{OC}$ power generation system, the factors with the largest and smallest range differences are $\mathrm{D}\left(\alpha_{\mathrm{O}_{2}}\right)$ and $\mathrm{C}\left(\chi_{1}\right)$, respectively. The influence of each operating factor on the net standard coal consumption rate and the net electrical efficiency of the $\mathrm{OC}$ power generation system is as follows: $\mathrm{D}\left(\alpha_{\mathrm{O}_{2}}\right)>\mathrm{B}\left(r_{\mathrm{O}_{2}}\right) \approx \mathrm{A}\left(\varphi_{\mathrm{O}_{2}}\right)>\mathrm{C}\left(\chi_{1}\right)$.

Table 6. Range analysis results of the net standard coal consumption rate orthogonal test (the unit is $\mathrm{g} / \mathrm{kW} \cdot \mathrm{h})$.

\begin{tabular}{ccccc}
\hline Experiment & A & B & C & D \\
\hline$K_{1 j}$ & 427.143 & 443.265 & 436.267 & 416.654 \\
$K_{2 j}$ & 429.329 & 436.467 & 433.450 & 424.163 \\
$K_{3 j}$ & 431.216 & 432.093 & 434.134 & 430.867 \\
$K_{4 j}$ & 434.550 & 429.373 & 430.912 & 443.448 \\
$K_{5 j}$ & 444.492 & 425.532 & 431.966 & 451.598 \\
$R_{j}$ & 17.349 & 17.733 & 5.355 & 34.944 \\
\hline
\end{tabular}

Table 7. Range analysis results of the net electrical efficiency orthogonal test (the unit is \%).

\begin{tabular}{ccccc}
\hline Experiment & A & B & C & D \\
\hline$K_{1 j}$ & 28.76 & 27.75 & 28.22 & 29.48 \\
$K_{2 j}$ & 28.64 & 28.20 & 28.35 & 28.97 \\
$K_{3 j}$ & 28.52 & 28.44 & 28.33 & 28.51 \\
$K_{4 j}$ & 28.29 & 28.63 & 28.52 & 27.72 \\
$K_{5 j}$ & 27.69 & 28.88 & 28.49 & 27.22 \\
$R_{j}$ & 1.07 & 1.13 & 0.30 & 2.26 \\
\hline
\end{tabular}

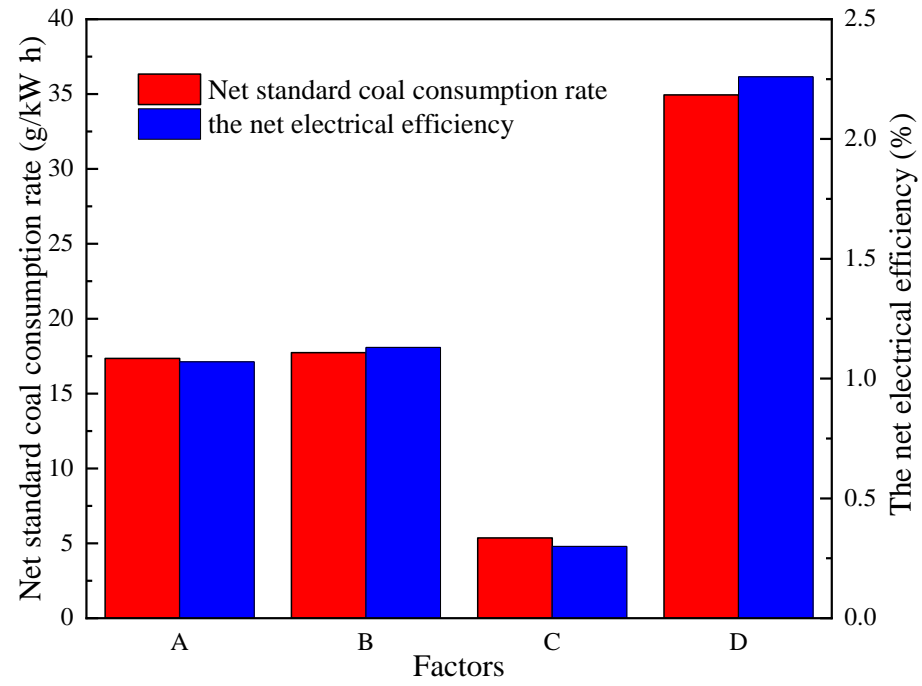

Figure 15. Range analysis of the net standard coal consumption rate and the net electrical efficiency corresponding to the four factors.

\subsubsection{Analysis of Variance by Orthogonal Test}

According to the calculation results of orthogonal design, the specific calculation equations of variance analysis $[21,31]$ are:

$$
\overline{K_{i j}}=\frac{r}{N} K_{i j}
$$




$$
\begin{gathered}
\bar{y}=\frac{1}{N} \sum_{i=1}^{n} y_{i} \\
S_{j}=\frac{N}{r} \sum_{i=1}^{n}\left(\overline{K_{i j}}-\bar{y}\right)^{2} \\
f_{j}=r-1 \\
\overline{S_{j}}=\frac{S_{j}}{f_{j}}
\end{gathered}
$$

where $r$ is the level number of factors, $N$ is the number of simulation calculations, $K_{i j}$ is the simulation result of factor $j$ at the $i$ level, $y_{i}$ is the $i$ th simulation result, $\bar{y}$ is the average of $n$ calculated results, $\overline{K_{i j}}$ is the average value of calculated results at the $i$ level of factor $j, S_{j}$ is the sum of deviation squares of any case, $f_{j}$ is the degrees of freedom, and $\overline{S_{j}}$ is the mean square sum.

The variance analysis of the orthogonal experiment separates the variance that belongs to the category of experimental error from the sum of square variances caused by experimental factors. We used the sum of the squares of deviation and error of each factor to construct the test statistics and conducted an $\boldsymbol{F}$-test to judge whether the effect of each factor was significant or not. The analysis of variance (ANOVA) can make up for the shortcomings of range analysis, determine whether each factor is significant to the test index and the magnitude of significance, and evaluate the error [21,22,31]. According to the calculation results of orthogonal design, the specific calculation equation of variance analysis is as follows:

The sum of the squares of deviations caused by the $j$ th factor column is

$$
S_{j}=\frac{r}{t} \sum_{i=1}^{r} K_{i j}^{2}-\frac{1}{t}\left[\sum_{i=1}^{r} K_{i j}\right]^{2}
$$

where $t$ is the test number of the $j$ factor at the $i$ level.

The sum of the squares of the deviations of all the empty columns in the interactive orthogonal table is called the sum of the squares of the random errors of the experiment, denoted as $S_{e}$. The deviation means square and $V_{j}$ of each factor, the random error mean square, and $V_{e}$ is:

$$
\begin{aligned}
& V_{j}=S_{j} / f_{j} \\
& V_{e}=S_{e} / f_{e}
\end{aligned}
$$

where $f_{j}$ is the degree of freedom, $f_{j}=r-1$, and $f_{e}$ is the sum of the degrees of freedom of each blank column.

Therefore, the corresponding statistic $F_{j}$ of each factor is:

$$
F_{j}=\frac{V_{j}}{V_{e}} \sim F\left(f_{j}, f_{e}\right)
$$

The symbol" $\sim$ " indicates that $F_{j}$ is compared with $F\left(f_{j}, f_{e}\right)$. The significance level of the $\boldsymbol{F}$-test was $0.10,0.05$, and 0.01 [22,31].

Tables 8 and 9 show that the excess oxygen coefficient has a particularly significant influence on the net standard coal consumption rate and the net electrical efficiency for the OC power generation system (confidence $P=99 \%$ ). The oxygen concentration and oxygen purity have a significant influence (confidence $P=95 \%$ ). The recirculation rate of dry flue gas in boiler flue gas does not have a significant influence (confidence $P=90 \%$ ). 
Table 8. Analysis results of the net standard coal consumption rate orthogonal test difference.

\begin{tabular}{cccccc}
\hline Factors & $\begin{array}{c}\text { Deviation Sum } \\
\text { of Squares }\end{array}$ & $\begin{array}{c}\text { Degrees of } \\
\text { Freedom }\end{array}$ & $\begin{array}{c}\text { Mean Sum of } \\
\text { Squares }\end{array}$ & F-Ratio & Significance \\
\hline Oxygen purity & 924.16 & 4 & 231.04 & 9.25 & $\star \star$ \\
Oxygen concentrations & 932.69 & 4 & 233.17 & 9.33 & $\star \star$ \\
$\chi_{1}$ & 84.98 & 4 & 21.25 & 0.85 & $\vdots$ \\
Excess oxygen coefficient & 4021.35 & 4 & 1005.34 & 40.23 & $\star \star \star$ \\
Error & 99.94 & 4 & 24.99 & & \\
\hline
\end{tabular}

Table 9. Analysis results of the net electrical efficiency orthogonal test difference.

\begin{tabular}{cccccc}
\hline Factors & $\begin{array}{c}\text { Deviation Sum } \\
\text { of Squares }\end{array}$ & $\begin{array}{c}\text { Degrees of } \\
\text { Freedom }\end{array}$ & $\begin{array}{c}\text { Mean Sum of } \\
\text { Squares }\end{array}$ & F-Ratio & Significance \\
\hline Oxygen purity & 3.498 & 4 & 0.875 & 11.738 & $\star \star$ \\
Oxygen concentrations & 3.703 & 4 & 0.926 & 12.426 & $\star \star$ \\
$\chi_{1}$ & 0.301 & 4 & 0.075 & 1.010 & $\vdots$ \\
Excess oxygen coefficient & 16.672 & 4 & 4.168 & 55.946 & $\star \star \star$ \\
Error & 0.298 & 4 & 0.075 & - & \\
\hline
\end{tabular}

Note: $F_{0.01}(4,4)=16.00, F_{0.05}(4,4)=6.39$, and $F_{0.10}(4,4)=4.11[22]$.

It is generally believed that when $F$ is greater than $F_{0.01}$, the influence of factors is particularly significant, denoted as " $\star \star \star$." When $F_{0.01} \geq F>F_{0.05}$, the influence of factors is significant, denoted as " $\star \star$." When $F_{0.05} \geq F>F_{0.10}$, the factors have a certain influence, denoted as " $\star$." When $F_{0.10}>F$, the influence of factors is not significant and is denoted as "交."

\section{Conclusions}

Many previous studies are available for OC power generation systems under different working conditions. However, few studies try to reveal the rules about how the working parameters influence the operating energy indexes in a uniform experiment or simulation platform, especially in a quantitative way. In the present study, we aimed to analyze the sensitivity of system parameters to the operating energy indexes of the OC power generation systems quantitatively, the orthogonal design method was adopted, and the sensitivity of four system parameters to the two indices of OC power generation systems was evaluated. We came to the following conclusions:

1. With an increase of oxygen purity, the increase of actual separation work required by air separation leads to the sharp increase in energy consumption of ASU. However, with the increase of oxygen purity, the reduction of boiler flue gas reduced the energy of the CPU. The superposition result of these two effects is as follows: with the increase of oxygen purity, the net standard coal consumption rate of the OC power generation system first decreased and then increased, while the net electrical efficiency of the OC power generation system first increased and then decreased. With the increase of oxygen concentration, the burnout rate of pulverized coal increased, leading to the decrease of combustion oxygen demand and flue gas in the OC power generation system. The result is that with the increase of oxygen concentration, the net coal consumption of the OC power generation system decreases, while the net electrical efficiency of the OC power generation system increases. The increase in $\chi_{1}$ increases the share of flue gas with high oxygen content for combustion, thus reducing the oxygen supply of air separation and flue gas. As a result, with the increase of $\chi_{1}$, the net standard coal consumption rate of the OC power generation system presents a downward trend, while the net electrical efficiency of the OC power generation system presents a rising trend. With the increase of the excess oxygen coefficient, the combustion oxygen flow rate and the flue gas volume of the boiler increase, leading to an increase in energy consumption of ASU and CPU. The result is that with the increase of excess oxygen coefficient, the net standard coal consumption rate increases and the net electrical efficiency decreases.

2. When oxygen purity, oxygen concentration, recirculation rate of dry flue gas in boiler flue gas, and excess oxygen coefficient are $96 \%, 33 \%, 55 \%$, and 1.05 , respectively, the net standard coal 
consumption rate of system reaches the lowest, and the net electrical efficiency of the system reaches the highest.

3. The orders of the four factors' sensitivity to the two indices are also obtained. The influence of each operating factor on the net standard coal consumption rate and the net electrical efficiency of the OC unit was as follows: excess oxygen coefficient $>$ oxygen concentration $\approx$ oxygen purity $>$ recirculation rate of dry flue gas in boiler flue gas Among the operating factors, the excess oxygen coefficient had a particularly significant influence on the net electrical efficiency and the net standard coal consumption rate of the power supply for OC power generation system. The influence of oxygen concentration and oxygen purity was significant. The influences of the recirculation rate of dry flue gas in boiler flue gas were not significant.

Author Contributions: Conceptualization, Z.Z. and Y.Y.; methodology, R.Z.; validation, X.W.; data curation, R.Z. and X.W.; writing — original draft preparation, Z.Z.; writing—review and editing, Z.Z.; project administration, Y.Y.; All authors have read and agreed to the published version of the manuscript.

Funding: This research was funded by Science Fund for Creative Research Groups of the National Natural Science Foundation of China, grant number 51821004; National Basic Research Program (973 Program), grant number 2015CB251505; National Natural Science Foundation of China, grant number 51776063; Natural science foundation of Inner Mongolia, grant number 2018MS05035 and 2018LH05012; Baotou science and technology project, grant number 2019Z3004-4 and the APC was funded by Science Fund for Creative Research Groups of the National Natural Science Foundation of China, grant number 51821004 and Baotou science and technology project, grant number 2019Z3004-4.

Acknowledgments: This work was supported by Science Fund for Creative Research Groups of the National Natural Science Foundation of China (51821004), National Basic Research Program (973 Program) (2015CB251505), National Natural Science Foundation of China (51776063), Natural science foundation of Inner Mongolia (2018MS05035,2018LH05012), and Baotou science and technology project (2019Z3004-4).

Conflicts of Interest: The authors declare no conflict of interest.

\section{Abbreviations}

ANOVA Analysis of variance

ASU Air separation unit

CPU Compressed purification unit of gas

EP The energy penalty due to carbon capture in an oxyfuel combustion power generation system

LHV Low heating value

TEG Triethylene glycol

OC Oxyfuel combustion

\section{References}

1. The Intergovernmental Panel on Climate Change (IPCC). IPCC's Fourth Assessment Report (AR4) (Cambridge); Cambridge University Press: Cambridge, UK, 2007; Available online: https://www.ipcc.ch/site/assets/ uploads/2018/02/ar4_syr_full_report.pdf (accessed on 17 November 2007).

2. Xiong, J.; Zhao, H.B.; Zheng, C.G. An economic feasibility study of $\mathrm{O}_{2} / \mathrm{CO}_{2}$ recycle combustion technology based on existing coal-fired power plants in China. Fuel 2009, 88, 1135-1142. [CrossRef]

3. Toftegaard, M.B.; Brix, J.; Jensen, P.A. Oxyfuel combustion of solid fuels. Prog. Energy Combust. Sci. 2010, 36, 581-625. [CrossRef]

4. Massachusetts Institute of Technology. The Future of Coal. Available online: http://web.mit.edu/coal/ (accessed on 14 March 2007).

5. Han, T.; Yu, X.H.; Liao, H.Y. Simulation and optimization of a triple-column cycle for oxygen production of 200 MW oxyfuel power plant. Electr. Power 2016, 49, 134-140. (In Chinese)

6. Jin, B.; Zhao, H.B.; Zheng, Ch. G. Dynamic energy method and its application for $\mathrm{CO}_{2}$ compression and purification unit in oxy-combustion power plants. Chem. Eng. Sci. 2016, 144, 336-345. [CrossRef]

7. Vittorio, T.; Giorgio, C.; Francesca, F. $\mathrm{CO}_{2}$ emissions reduction from coal-fired power generation: A techno-economic comparison. J. Energy Resour. Technol. 2016, 138, 42-51. 
8. Oboirien, B.O.; North, B.C.; Kleyn, T. Techno-Economic assessments of oxyfuel technology for South African coal-fired power stations. Energy 2014, 66, 550-555. [CrossRef]

9. Fu, C.; Anantharaman, R.; Gundersen, T. Optimal integration of compression heat with regenerative steam Rankine cycles in oxy-combustion coal based power plants. Energy 2015, 84, 612-622. [CrossRef]

10. Yan, K.; Wu, X.J.; Hoadley, A.; Xu, X.Y.; Zhang, J.; Zhang, L. Sensitivity analysis of oxyfuel power plant system. Energy Convers. Manag. 2015, 98, 138-150. [CrossRef]

11. Paweł, G.; Andrzej, Z. Life cycle assessment of an integrated oxyfuel combustion power plant with $\mathrm{CO}_{2}$ capture, transport and storage-Poland case study. Energy 2015, 92, 328-340.

12. Koiwanit, J.; Manuilova, A.; Chan, C.; Wilson, M.; Tontiwachwuthikul, P. A life cycle assessment study of a hypothetical Canadian oxyfuel combustion carbon dioxide capture process. Int. J. Greenh. Gas. Control. 2014, 28, 257-274. [CrossRef]

13. Jin, B.; Zhao, H.B.; Zou, C. Comprehensive investigation of process characteristics for oxy-steam combustion power plants. Energy Convers. Manag. 2015, 99, 92-101. [CrossRef]

14. Kong, H.B.; Liu, C.H.; Chen, S. Process simulation and optimization of a $600 \mathrm{MW} \mathrm{O}_{2} / \mathrm{CO}_{2}$ power plant. Proc. CSEE 2012, 32, 53-60. (In Chinese)

15. Han, D.; Duan, L.B.; Duan, Y.F.; Hu, H.H.; Pan, X. Process simulation and optimization of oxyfuel combustion system. J. China Coal Soc. 2013, 38, 2241-2246. (In Chinese)

16. Escudero, A.I.; Espatolero, S.; Romeo, L.M.; Lara, Y.; Paufique, C.; Lesort, A.L.; Liszka, M. Minimization of $\mathrm{CO}_{2}$ capture energy penalty in second generation oxyfuel power plants. Appl. Therm. Eng. 2016, 103, 274-281. [CrossRef]

17. Gladysz, P.; Ziebik, A. Complex energy analysis of an integrated oxyfuel combustion power plant with $\mathrm{CO}_{2}$ transport and storage. Energy 2015, 95, 23-31.

18. Ziebik, A.; Gladysz, P. System approach to the analysis of an integrated oxyfuel combustion power plant. Arch. Thermodyn. 2014, 35, 39-57. [CrossRef]

19. Lei, M.; Sun, C.; Wang, C. Techno-Economic analysis of a $600 \mathrm{MW}$ oxy-enrich pulverized coal-fired boiler. Energies 2018, 11, 768 .

20. Gao, D.M.; Chen, H.W.; Yang, J.M.; Gu, J.J. Influence factor analysis of circulating fluidized bed boiler oxyfuel combustion and $\mathrm{CO}_{2}$ capture power generation unit operation energy consumption. Proc. CSEE 2019, 39, 1387-1396. (In Chinese)

21. Raghu, N.K.; Lagergren, E.S.; Filliben, J. Taguchi's orthogonal arrays are classical designs of experiments. J. Res. Natl. Inst. Stand. Technol. 1991, 96, 577-591.

22. Ren, L.Q. Optimum Design and Analysis of Experiments; Higher Education Press: Beijing, China, 2003.

23. Wang, X.; Liu, X.M.; Zhang, C. Parametric optimization and range analysis of Organic Rankine Cycle for binary-cycle geothermal plant. Energy Convers. Manag. 2014, 80, 256-265. [CrossRef]

24. Liu, X.M.; Wang, X.; Zhang, C.H. Sensitivity analysis of system parameters on the performance of the Organic Rankine Cycle system for binary-cycle geothermal power plants. Appl. Therm. Eng. 2014, 71, 175-183. [CrossRef]

25. Xi, H.; Zhang, H.H.; He, Y.L.; Huang, Z.H. Sensitivity analysis of operation parameters on the system performance of organic rankine cycle system using orthogonal experiment. Energy 2019, 172, 435-442. [CrossRef]

26. Chiu, Y.J.; Chiu, H.C.; Hsieh, R.H.; Jang, J.H.; Syu, G.J. Experimental study on the reaction conditions of a methanol steam reforming process. Energy Procedia 2017, 105, 1622-1627. [CrossRef]

27. Chen, W.H.; Huang, S.R.; Lin, Y.L. Performance analysis and optimum operation of a thermoelectric generator by Taguchi method. Appl. Energy 2015, 158, 44-54. [CrossRef]

28. Terzioğlu, H. Analysis of effect factors on thermoelectric generator using Taguchi method. Measurement 2020, 149, 106992. [CrossRef]

29. Aspen Plus, Aspentech. Available online: http://www.aspentech.com, (accessed on 10 December 2014).

30. EBSILON professional, STEAG Gmbh. Available online: https://www.steag-systemtechnologies.com/en/ products/ebsilon-professional (accessed on 12 December 2017).

31. Montgomery, D.C. Design and analysis of experiments, 9th ed.; Wiley: Hoboken, NJ, USA, 2017; pp. 67-75.

(C) 2020 by the authors. Licensee MDPI, Basel, Switzerland. This article is an open access article distributed under the terms and conditions of the Creative Commons Attribution (CC BY) license (http://creativecommons.org/licenses/by/4.0/). 